\title{
Ozone time scale decomposition and trend assessment from surface observations in Switzerland.
}

\author{
Eirini Boletia ${ }^{\mathrm{a}, \mathrm{b}}$, Christoph Hueglin ${ }^{\mathrm{a}, *}$, Satoshi Takahama ${ }^{\mathrm{b}}$ \\ ${ }^{a}$ Empa, Swiss Federal Laboratories for Materials Science and Technology, Überlandstrasse \\ 129, Dübendorf, Switzerland \\ ${ }^{b}$ EPFL, École Polytechnique Fédérale de Lausanne, Route Cantonale, 1015 Lausanne, \\ Switzerland
}

\begin{abstract}
Regulation for ozone $\left(\mathrm{O}_{3}\right)$ precursor emissions began in Europe around 1990 with control measures primarily targeting industries and traffic. To understand how these measures have affected air quality, it is important to investigate the temporal evolution of tropospheric $\mathrm{O}_{3}$ concentrations in different types of environments. In this study, we analyze long-term trends of the concentrations of $\mathrm{O}_{3}$ and the sum of oxidants $\mathrm{O}_{x}\left(\mathrm{O}_{3}+\mathrm{NO}_{2}\right)$ in Switzerland for the last 25 years. Statistical decomposition of the observed time series is used to extract the underlying time scales, i.e. the long-term, seasonal and short-term variability. This allows subtraction of the seasonal variation of $\mathrm{O}_{3}$ and $\mathrm{O}_{x}$ from the observations and estimation of long-term changes of de-seasonalized $\mathrm{O}_{3}$ and $\mathrm{O}_{x}$ with reduced uncertainties. A two-regime trend calculation based on the long-term variability accounts for non-monotonic temporal evolution of $\mathrm{O}_{3}$. In addition, adjustment of the higher frequency meteorological influence was applied, based on the time series containing the short-term variability. This led to an uncertainty reduction in the trend estimation, but only by a small factor. We observe that, despite the implementation of regulations and reduction of nitrogen oxides concentrations, for all studied sites daily mean $\mathrm{O}_{3}$ values increased until mid-2000s. Afterwards, a decline or a leveling-off in the concentrations is
\end{abstract}

\footnotetext{
* Corresponding author

Email address: Christoph.Hueglin@empa.ch (Christoph Hueglin)
}

This document is the accepted manuscript version of the following article:

Boleti, E., Hueglin, C., \& Takahama, S. (2018). Ozone time scale decomposition and trend assessment from surface observations in Switzerland. Atmospheric Environment, 191, 440-451. https://doi.org/10.1016/j.atmosenv.2018.07.039 
observed. The start of change in the trend depends on the site type; the more polluted the site, the later is the onset of the change in trend behavior. At locations close to sources, the observed trend can mainly be explained by the reduced titration of $\mathrm{O}_{3}$ by $\mathrm{NO}$ due to the strong reductions in nitrogen oxides emissions. At remote locations (such as the high alpine station in Jungfraujoch) that are influenced by hemispheric transport of $\mathrm{O}_{3}$ an increase during 1990s and a decline after early 2000s is observed. The calculated temporal trends exhibit distinct differences depending on the characteristics and pollution burdens of the measurement sites; such differences have become smaller following emission reductions.

Keywords: ozone, time scale decomposition, trend analysis, meteorological adjustment

\section{Introduction}

Tropospheric ozone $\left(\mathrm{O}_{3}\right)$ is an important trace gas for air quality and is recpgnized as a threat for human health and agriculture (World Health Organization, 2013, LRTAP Convention, 2015, National Research Council, 1992). It also

5 acts as a greenhouse gas with globally averaged radiative forcing $0.4 \pm 0.2 \mathrm{~W} / \mathrm{m}^{2}$ (IPCC, 2013). $\mathrm{O}_{3}$ either originates naturally in the stratosphere (Junge, 1962. Stohl et al. 2003) or is produced in the troposphere by photochemical reactions. These reactions involve sunlight and anthropogenic and natural $\mathrm{O}_{3}$ precursor gases, in particular nitrogen oxides $\left(\mathrm{NO}_{x}=\mathrm{NO}_{2}+\mathrm{NO}\right)$, volatile organic compounds (VOCs), methane $\left(\mathrm{CH}_{4}\right)$ and carbon monoxide $(\mathrm{CO})$ Maas and Grennfelt, 2016 Monks et al., 2015). Biogenic emissions are also known to have a positive effect on production of tropospheric $\mathrm{O}_{3}$ mainly through reduction of the hydroxyl radical $(\mathrm{OH})$ (Simpson, 1995). Emissions of $\mathrm{O}_{3}$ precursors, $\mathrm{NO}_{x}$ and VOCs, have been declining in Europe and the U.S. since the 1990s due to implementation of emission control measures (Colette et al. 2011, Guerreiro et al. 2014, Henschel et al. 2015; Granier et al., 2011). For example, the Gothenburg Protocol, implemented in 1999 and revised in 2012, tackles acidification, eu- 
trophication and ground-level $\mathrm{O}_{3}$ in Europe, through reduction of emissions of $\mathrm{NO}_{x}$, VOCs, sulfur dioxide $\left(\mathrm{SO}_{2}\right)$ and ammonia $\left(\mathrm{NH}_{3}\right)$. Colette et al. (2011) calculated air pollutant trends for the period 1998-2007 and observed a decrease in $\mathrm{NO}_{2}$ concentrations across most of Europe, which is more pronounced in urban areas. In addition, VOC and $\mathrm{NO}_{x}$ emissions have decreased by $40 \%$ and $35 \%$ respectively in the European Union (Maas and Grennfelt, 2016). In Switzerland, emissions of $\mathrm{NO}_{x}$ and VOCs peaked in the mid- or late 1980s and decreased by around $30-40 \%$ in the 1990s (BAFU, 2016; Stiller et al. 2000). Since the beginning of the 2000s their decrease has been less pronounced (BAFU, 2016). Due to emission reductions of $\mathrm{O}_{3}$ precursors, it was expected that $\mathrm{O}_{3}$ concentrations across Europe would decline as well, as has been supported by trend estimates since 2000 (Chang et al., 2017). However, mean concentration of tropospheric 30 $\mathrm{O}_{3}$ in Europe was increasing in the 1990s and early 2000s (Wilson et al., 2012). Therefore, it is important to investigate and understand how tropospheric $\mathrm{O}_{3}$ levels have changed over the last decades.

As stated in the report of the European Environmental Agency (EEA), observed $\mathrm{O}_{3}$ trends suffer from large uncertainties associated with current trend analysis practices (Guerreiro et al. 2016). The investigation of long-term trends of $\mathrm{O}_{3}$ due to policy decisions is obfuscated by its strong intra- and inter-annual variability. Analysis of annually-averaged concentrations eliminates the intraannual variability on the trend estimate, but this leads to a loss of statistical sample size and the influence of inter-annual variability occurring on shorter timescales than the desired trend signal remains. A solution to this problem is to decompose the observed $\mathrm{O}_{3}$ concentrations into the underlying frequency modes (Chang et al., 2017); trends can be calculated from the long-term and deseasonalized signal isolated by this approach. Additional variability that occurs on shorter time scales due to meteorological factors can be subject to statistical 45 adjustment for refined trend analysis.

The main goal of this study is to describe and understand the response of $\mathrm{O}_{3}$ to the reductions of $\mathrm{NO}_{x}$ and VOCs after implementation of measures since the 1990s. Thus, long-term observational data from Swiss sites were used for 
investigation of the temporal trends in surface $\mathrm{O}_{3}$ and the sum of oxidants $\mathrm{O}_{x}$ $\left(\mathrm{O}_{x}=\mathrm{O}_{3}+\mathrm{NO}_{2}\right)$ for the last 25 years. In our approach, a time-scale decomposition is applied on the available time series in order to identify the underlying contributions from the long-term, seasonal and short-term variability. The seasonal variability is removed from the observations to obtain the de-seasonalized $\mathrm{O}_{3}$ time series. Guided by the measurements, a two-regime trend analysis is used to address non-monotonic temporal evolution of $\mathrm{O}_{3}$. The specific for each station date of change in the trend is assessed via the long-term variability, and the trend is calculated in two separate periods. In addition, the short-term variations of $\mathrm{O}_{3}$ and $\mathrm{O}_{x}$ are correlated with meteorological parameters of the same time scale to adjust the observations for the influence of meteorological conditions. The methodology is discussed in detail in Section 3, and the results are presented in Section 4.

\section{Data}

Measurements were provided by the regulatory air quality monitoring networks operated by the Swiss federal and cantonal authorities at 1-hour resolution between 1990 and 2014. The stations used for this study have a data availability of more than $95 \%$ (Table 1 and Fig. 4), and the metrics considered are the following: daily mean, daily maximum of 8 hour running mean of hourly $\mathrm{O}_{3}$ concentrations (MDA8, European Parliament and Council of the European Union, 2008), and daily mean of $\mathrm{O}_{x}$. Note that this study is focused on daily average $\mathrm{O}_{3}$ and $\mathrm{O}_{x}$ concentrations, a complementary study focusing on the trend of daily peak $\mathrm{O}_{3}$ is under preparation (Boleti et al., 2018). The decomposition method used here requires complete time series and therefore gap filling is needed in order to proceed. Missing values in the data set are treated as follows: (a) an average year is calculated from the mean values of the observed concentrations for each calendar day, (b) the positions of the missing values are identified, and (c) filled with the corresponding value from the calculated average year. Percentages of missing values vary between $0.32-4.27 \%$ and number of 
successive missing values in the data are between 4-16 days (except for Tänikon and Grenchen 40 days, Jungfraujoch 43 days and Thônex-Foron 92 days).

For the meteorological adjustment of $\mathrm{O}_{3}$, information for several meteorological variables was taken from measurements at the respective site and includes: temperature $\left({ }^{\circ} \mathrm{C}\right)$, humidity $(\%)$, solar radiation $\left(\mathrm{W} \cdot \mathrm{m}^{-2}\right)$, surface pressure $(\mathrm{hPa})$, wind velocity $\left(\mathrm{m} \cdot \mathrm{s}^{-1}\right)$ and precipitation $(\mathrm{mm})$. For data sets with more than $5 \%$ and /or more than 30 successive days of missing values, meteorological data were taken from nearby sites operated by MeteoSwiss. Otherwise, missing values during less than $5 \%$ of the time and/or less than 30 continuous days were replaced by linear interpolation. For the stations in Frauenfeld and Grenchen, no complete meteorological information was available; therefore, only the de-seasonalization approach was applied without further meteoadjustment. For a more complete description of the meteorological situation, additional meteorological variables were derived from the European reanalysis data-set (ERA-Interim) (Dee et al., 2011) in 1 degree resolution at the location (longitude-latitude-altitude) of each station, i.e. boundary layer height (m), convective available potential energy (CAPE, $\mathrm{J} \cdot \mathrm{kg}^{-1}$ ), sensible surface heat flux $\left(\mathrm{W} \cdot \mathrm{m}^{-2}\right)$ and total cloud cover. Additionally, we considered the synoptic situation as a meteorological variable, provided as weather type classifications (WTCs, Weusthoff, 2011) from MeteoSwiss, that describe recurrent dynamical patterns. The categories include classification with $3 \times 8$ wind directions (cyclonic, anticyclonic and indifferent) and low/high pressure based on mean sea level pressure, which yields 26 different synoptic patterns. All meteorological variables, both observations and derived variables, are used in daily average resolution.

\section{Methods}

The procedure applied in the present trend analysis consists of the following steps: 1) decomposition of daily mean $\mathrm{O}_{3}, \mathrm{MDA} 8$ and daily mean $\mathrm{O}_{x}$ observations for each station into the underlying frequencies and calculation of 
long-term, seasonal, and short-term variation, 2) subtraction of the seasonal variation from the observations and calculation of the absolute trend (in ppb per year) on the de-seasonalized time series, 3) decomposition of meteorological variables into long-term, seasonal, and short-term variation and 4) adjustment of the observations for the short-term meteorological influence and calculation of trends based on the meteo-adjusted time series. The extracted long-term variability shows for most stations a change in sign after mid-2000s, and the exact time of change appears to be different for each station. For this reason, at sites where this change occurs, the slopes are calculated in two regimes, the period before and after the change, first and second period respectively. In the following, we present in detail the steps and methods performed for the current trend analysis.

\subsection{De-seasonalized trends}

The de-seasonalization of $\mathrm{O}_{3}$ observations first requires the extraction of a representative seasonal signal. For this reason, a time scale decomposition was performed based on both a non-parametric and a parametric method. Similar to Kuebler et al. (2001), this decomposition assumes that the signal can be viewed as

$$
y(t)=L T(t)+S(t)+W(t)+E(t)
$$

where $y(t)$ are the observations, $L T(t)$ stands for the long-term variation, $S(t)$ the seasonal variation, $W(t)$ the short-term variation, and $E(t)$ the remainder of the decomposition. $L T(t)$ represents variations at multiannual timescales, $S(t)$ variations at monthly to yearly timescales, and $W(t)$ variations at daily to monthly timescales.

\subsubsection{De-seasonalization with non-parametric approach}

The non-parametric time scales decomposition was performed with the ensemble empirical mode decomposition (EEMD, Huang et al. (1998); Huang and $\mathrm{Wu}$ (2008); Wu and Huang (2009)). The method resolves the non-overlapping 
frequencies contained in the signal into a number of components. Each com-

ponent represents a distinct frequency, from highest to lowest, that is hidden in the original signal. This procedure was performed using the hht library in R (R Development Core Team, 2017). The long-term, seasonal and short-term variabilities were obtained by combining the associated frequencies.

The choice of the EEMD as a decomposition method is based on the fact that EEMD, in contrast to other methods (e.g. Fourier transformation), is entirely data driven. This formulation means that the results do not rely on a priori assumptions regarding the nature of the data (e.g. stationarity, periodicity). In addition, the basis functions are not predefined but extracted directly from the data (Huang and $\mathrm{Wu}$, 2008). Therefore, EEMD is considered an appropriate method for the analysis of non-linear and non-stationary time series.

घ The core of EEMD is the empirical mode decomposition (EMD, Huang et al., 1998, Huang and $\mathrm{Wu}, 2008$ ). In EMD, a number of so-called intrinsic mode functions (IMFs) are calculated, with each of the IMFs representing one distinct frequency in the signal. Consequently,

$$
y(t)=\sum_{j=1}^{n} c_{j}+r_{n}
$$

where $y(t)$ is the input data, $c_{j}$ the different IMFs, and $r_{n}$ the remainder of the decomposition.

The IMFs are calculated through an iterative sifting process (Fig. 1). First, the maxima and minima of $y(t)$ for each period in the signal are identified, and cubic splines are fitted to these extrema to form an upper and a lower envelope, representing the maxima and minima respectively. Then the mean of the upper and lower envelopes is calculated $\left(m_{1}\right)$ and subtracted from the input data, leading to the first protomode $\left(h_{1}\right)$. The first protomode serves as the input data for the second iteration, and the procedure is repeated $k$ times until the following stopping criteria are fulfilled: (a) the number of extrema and the number of zero crossings are equal or differ by at most one, and (b) the sum of 
the envelopes that define the local extrema is zero. After $k$ iterations,

$$
h_{1(k-1)}-m_{1 k}=h_{1 k}
$$

and, eventually, the $h_{1 k}$ will be the first IMF that contains the highest frequency. Next, the first IMF is subtracted from the original time series. The resulting signal is used as the input for the next sifting process, which leads to extraction of the second IMF of lower frequency $\left(h_{2 k}\right)$. This procedure results in a number of IMFs and a residue. The decomposition stops when the remaining series is a monotonic function or has only one extreme.
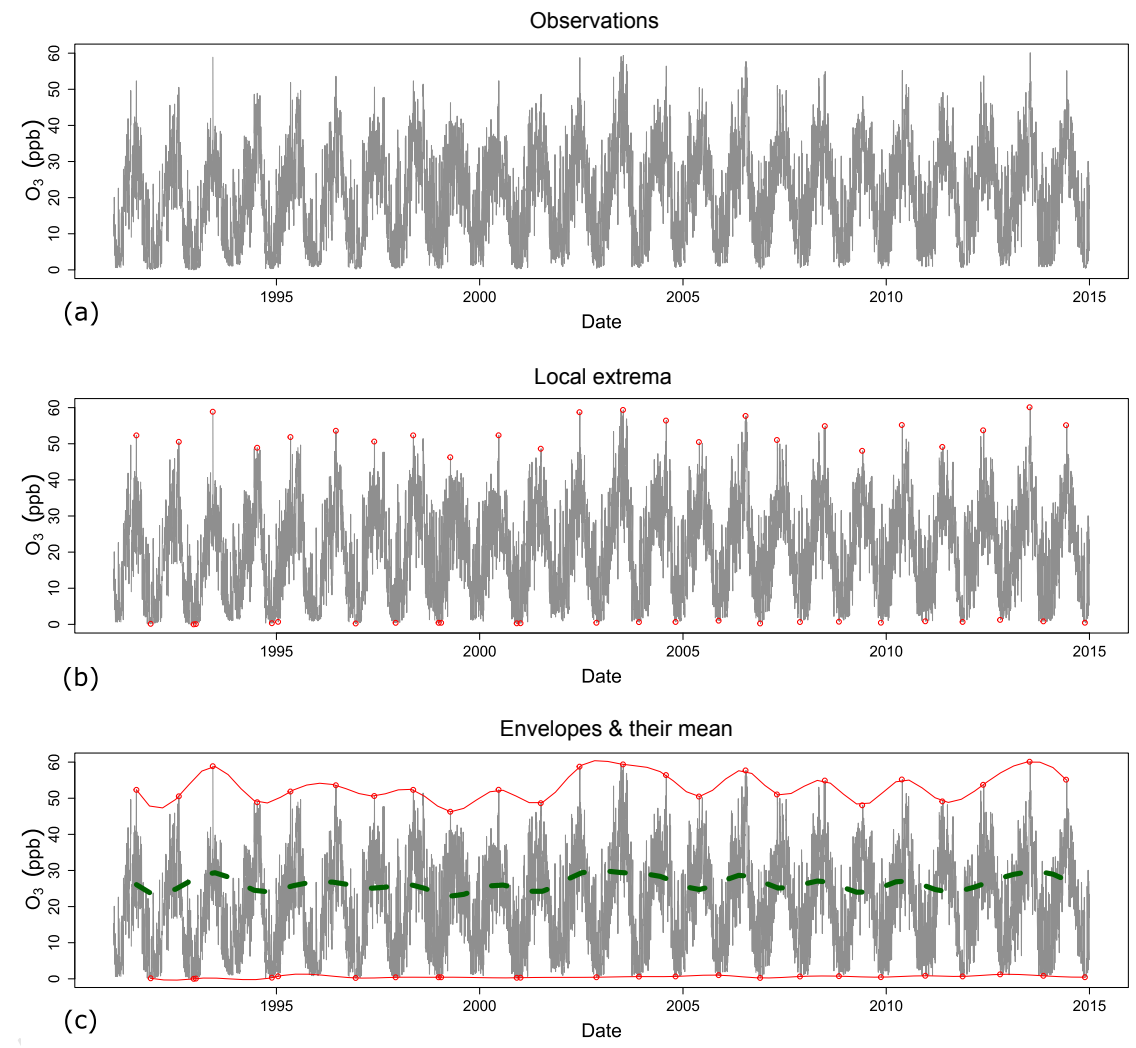

Figure 1: Example of the procedure for calculating an IMF for daily mean $\mathrm{O}_{3}$ concentrations (data set from Dübendorf). Red dots show the local extrema of the signal and red lines the fitted envelopes based on these extrema. The green dashed line is the mean of the upper and lower envelope. 


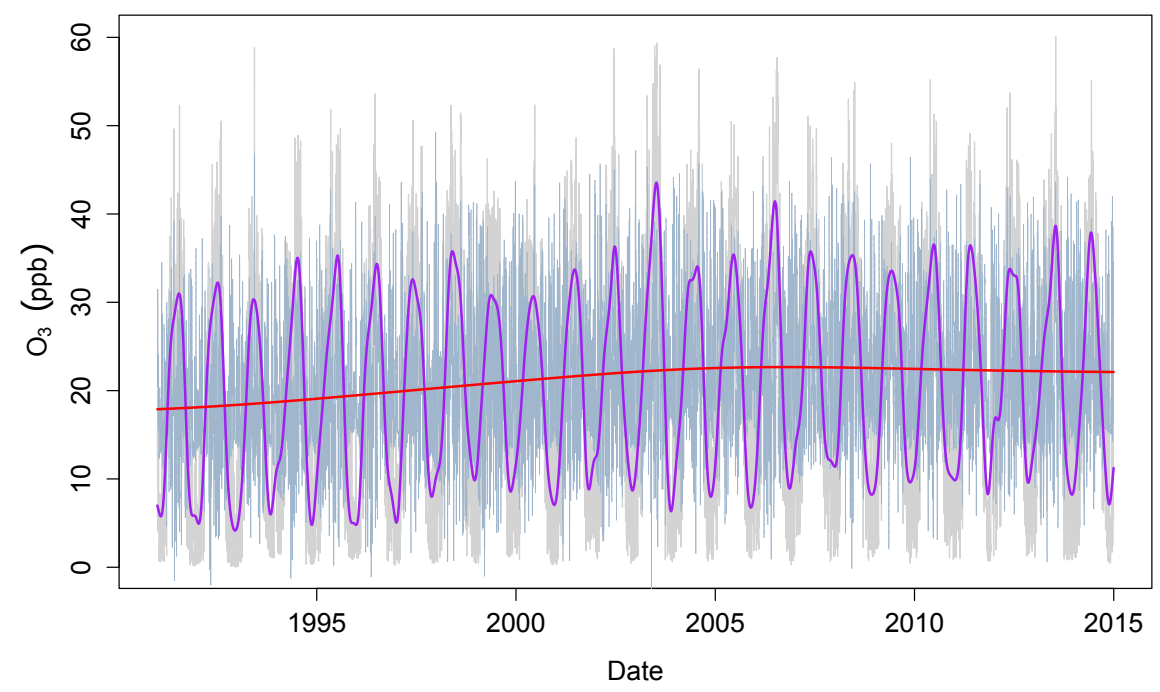

Figure 2: EEMD results for daily mean $\mathrm{O}_{3}$ concentrations in Dübendorf, a suburban background site. Shown is the daily mean observations (gray line), the long-term variation (red line) yielded from the residue of the EEMD, the seasonal variation (purple line) by adding together the IMFs 7-11 and the short term variation (light blue line) from the IMFs 1-6. For illustration reasons, the long-term signal was added to the seasonal and short-term signals.

EMD has some serious drawbacks in interpreting the physical meaning of the IMFs, caused by mode mixing, i.e. mixing of different frequencies in the same

IMF. Therefore, the updated method EEMD is proposed by Wu and Huang (2009). In EEMD, the final IMFs are calculated as the ensemble mean of a sufficient number of EMD trials, where white noise has been added to the signal at each trial. The amplitude of the added white noise and the number of trials required were investigated and results are presented in the supplementary material. In our case 150 trials were found to lead to robust solutions, and this number was used for all EEMD analyses in this study. The frequencies of the IMFs were obtained by means of periodograms (see supplementary material). The IMFs with periods between approximately 3 days and 3 months (IMFs 1-6) have been merged to represent the short-term variation with a resulting period 
of around 50 days. Periods between approximately 3 months and 3 years (IMFs 7-11) represent the seasonal variation with a period of around 11-12 months. Finally, the residue of the EEMD represents the long-term variation with a period longer than 3 years (Fig 2). The observed increase in $\mathrm{O}_{3}$ long-term trend during the 1990s and the decrease after mid-2000s in the case of Dübendorf prevails in almost all studied sites. Therefore, a two-regime trend approach will be used here as the basis for identifying trends in two separate time periods with a breakpoint in between, i.e. the date where the change in the trend occurs.

\subsubsection{De-seasonalization with parametric approach}

To validate and compare the results based on the EEMD, the time scale decomposition was additionally performed using a parametric approach. This procedure was carried out by fitting the sum of harmonic functions and polynomial terms to the observations (Thoning et al., 1989; Novelli et al., 1998). More precisely, the long-term variation is represented by

$$
L T(t)=c_{1} \cdot t+c_{2} \cdot t^{2}+c_{3} \cdot t^{3}
$$

and the seasonal variation is estimated by

$$
S(t)=\sum_{i=1}^{3}\left[a_{i} \cdot \sin (2 \pi t)+b_{i} \cdot \cos (2 \pi t)\right], i=1-3 .
$$

$c_{i}$ are the coefficients of a third-degree linear fit on the data and $a_{i}, b_{i}$ the coefficients of a sinusoidal fit. After subtracting $\mathrm{L}(\mathrm{t})$ and $\mathrm{S}(\mathrm{t})$ from the observations $(\mathrm{y}(\mathrm{t}))$ we obtain the short-term variation $(\mathrm{W}(\mathrm{t}))$ with periods ranging from days to months. Evidently, the seasonal signal has a periodicity of one year.

This comparison reveals the effect of the seasonal signal used in the deseasonalization process on the uncertainty in the trend estimation. Fig 3 shows a comparison of the two seasonal variations (parametric and non-parametric) obtained at the suburban site Dübendorf. It can be seen that the parametric approach has no explicit representation of the inter-annual variability. In contrast, the EEMD (non-parametric) accounts for the year-to-year variability in the signal due to varying meteorological conditions (e.g. untypically warm summer or 


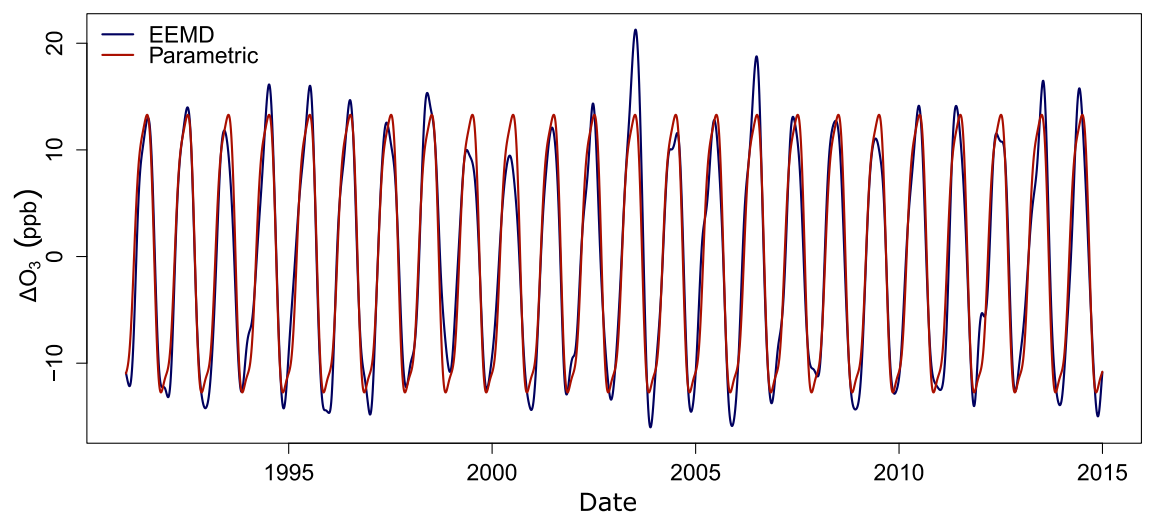

Figure 3: Seasonal variation signals for daily mean $\mathrm{O}_{3}$ concentrations in Dübendorf, obtained from the EEMD and from the parametric approach.

winter), therefore, the parametric approach is considered disadvantageous for the de-seasonalization process.

\subsubsection{Trends estimation}

The de-seasonalized time series of the studied $\mathrm{O}_{3}$ metrics are obtained by subtracting the seasonal variation from the observations, i.e.

$$
y_{d}(t)=y(t)-S(t)
$$

where $y_{d}(t)$ is the de-seasonalized time series.

The trend estimate is obtained by calculation of the Theil-Sen slope (Theil, 1950, Sen, 1968), where $y_{d}(t)$ is aggregated to monthly mean values. The uncertainty of the calculated trend in terms of the $95 \%$ confidence interval (CI) is obtained by bootstrapping. This means that slopes are calculated multiple times blockwise with replacement of resampled data (599 times for each block; each block has length $n^{1 / 3}$, where $n$ is the size of the sample). The $95 \%$ CI is determined from the variability of the Theil-Sen slopes obtained from the resampled data.

The breakpoint of the time series is identified in the long-term signal $(L T(t))$ 
as obtained from the EEMD analysis for each station separately. The exact time of change (if it exists) is determined as the time when the first derivative of the long-term signal changes sign.

\subsection{Meteo-adjusted trends}

Trend estimation is affected by the influence of meteorology on $\mathrm{O}_{3}$ concentrations. Therefore, observations have been adjusted for the higher frequency meteorological effects, and trends were calculated on the meteo-adjusted data, based on both the non-parametric and the parametric approach.

This was done by estimating the relationship between $\mathrm{O}_{3}$ and $\mathrm{O}_{x}$ concentrations and meteorological variables that are expected to have an effect on tropospheric $\mathrm{O}_{3}$. More specifically, the effect of short-term meteorological variations pn $\mathrm{O}_{3}$ is modeled using generalized additive models (GAMs, Hastie and Tibshirani, 1990, Wood, 2006). GAMs are known to perform well in studying the relationship between meteorological phenomena and air pollutants concentrations (e.g. Barmpadimos et al. (2011)). A GAM that consists of both numerical and categorical explanatory variables can generally be written as:

$$
y(t)=\alpha+\sum_{i=1}^{n} s_{i}\left(M_{i}(t)\right)+\sum_{j=1}^{m}\left(\sum_{k=1}^{p} b_{j k}\left(B_{j k}(t)\right)\right)+\epsilon(t)
$$

where $y(t)$ is the considered time series (here the short term signal of the considered $\mathrm{O}_{3}$ metrics), $\alpha$ is the intercept, $s_{i}$ are smooth functions of the numeric meteorological variables $M_{i}$. $B_{j k}$ denote the $j t h$ categorical variable in the model with $j$ indicating the categorical variable and $k$ the level of the categorical variable. $b_{j k}$ are the estimated effects of the categorical variables. Finally, $\epsilon(t)$ are the model residuals.

The advantage of GAMs is that they are very flexible and capable to account for non-linear relationships between meteorological variables and $\mathrm{O}_{3}$. The 245 GAMs were estimated using the mgcv library in R R Development Core Team, 2017). The meteorological parameters used in the GAMs as predictors are the following: (a) numeric: temperature, humidity, solar radiation, surface pressure, wind velocity, precipitation, height of the boundary layer, CAPE, sensible 
surface heat flux, total cloud cover and (b) categorical: day of the week and

WTCs.

Time series of all numerical meteorological variables were decomposed into long-term, seasonal, and short-term variation using the EEMD and the parametric approach described in Section 3.1.2.

$$
m(t)=L T_{m}(t)+S_{m}(t)+W_{m}(t)+E_{m}(t)
$$

where subscript $m$ indicates the meteorological variables mentioned above and $W_{m}(t)=0$ for the parametric approach. Then, the relationship between the signals of the short-term variations of the $\mathrm{O}_{3}$ metrics and the meteorological variables was estimated using GAMs.

$$
\begin{gathered}
W(t)=G A M\left(W_{m}(t)\right)+\epsilon_{W} \\
E(t)=G A M\left(E_{m}(t)\right)+\epsilon_{E}
\end{gathered}
$$

where $\epsilon_{W}$ and $\epsilon_{E}$ are the model residuals. Note that only equation 10 applies for the parametric approach.

The variation explained by the short-term meteorological effects, as captured by the GAMs, has been removed from the de-seasonalized data as follows:

$$
y_{\text {met.adj }}(t)=L T(t)+\epsilon_{W}+\epsilon_{E}
$$

where $y_{\text {met.adj }}$ stands for the meteo-adjusted time series of the daily mean $\mathrm{O}_{3}$, MDA8 $\mathrm{O}_{3}$ and daily mean $\mathrm{O}_{x}$. Note that for the parametric approach $e_{W}=0$ in equation 11. The meteo-adjusted trends were calculated using the Theil-Sen trend estimator in two regimes, as determined for the de-seasonalized trends.

\section{Results}

4.1. Comparison of long-term trends based on EEMD and the parametric approach

In Fig,5, bar-plots of the daily mean $\mathrm{O}_{3}$ trends based on the parametric approach and the non-parametric EEMD are presented. In addition, trends directly calculated with the Theil-Sen estimator applied to the annual mean $\mathrm{O}_{3}$ 
Table 1: Studied stations in Switzerland, ranked by increasing mean $\mathrm{NO}_{x}$ concentration from top to the bottom. The duration of the data set is also shown. Stations are categorized according to mean $\mathrm{NO}_{x}$ value during the studied period, where $\mathrm{A}$ : $N O_{x} \leq 1 \mathrm{ppb}, \mathrm{B}: 1 \leq$ $N O_{x} \leq 10 \mathrm{ppb}, \mathrm{C}: 10 \leq N O_{x} \leq 20 \mathrm{ppb}, \mathrm{D}: 20 \leq N O_{x} \leq 40 \mathrm{ppb}$, and E: $N O_{x} \geq 40$ ppb. (Cat. indicates the station's category.)

\begin{tabular}{|c|c|c|c|c|c|}
\hline Station & Code & Type & $\mathbf{N O}_{x}(\mathbf{p p b})$ & Time Period & Cat. \\
\hline Jungfraujoch & JUN & Remote, High Alpine (3578 m a.s.l.) & 0.34 & $1990-2014$ & A \\
\hline Davos & DAV & Rural, Elevated (>1000 m a.s.l.) & 2.87 & $1991-2014$ & $\mathrm{~B}$ \\
\hline Chaumont & $\mathrm{CHA}$ & Rural, Elevated (>1000 m a.s.l.) & 4.16 & $1991-2014$ & $\mathrm{~B}$ \\
\hline Rigi & RIG & Rural, Elevated (>1000 m a.s.l.) & 4.73 & $1991-2014$ & $\mathrm{~B}$ \\
\hline Tänikon & TAE & Rural, Background & 11.38 & $1990-2014$ & $\mathrm{C}$ \\
\hline Payerne & PAY & Rural, Background & 11.57 & $1990-2014$ & $\mathrm{C}$ \\
\hline Grenchen-Zentrum & GRE & Urban, Background & 21.00 & $1990-2014$ & $\mathrm{D}$ \\
\hline Basel-Binningen & BAS & Suburban, Background & 22.28 & $1990-2014$ & $\mathrm{D}$ \\
\hline Frauenfeld & FRA & Suburban, Background & 26.13 & $1995-2014$ & $\mathrm{D}$ \\
\hline Magadino & MAG & Rural, Background & 26.17 & $1991-2014$ & $\mathrm{D}$ \\
\hline Thônex-Foron & FOR & Suburban, Background & 30.75 & $1990-2014$ & $\mathrm{D}$ \\
\hline Dübendorf & DUE & Suburban, Background & 31.45 & $1991-2014$ & $\mathrm{D}$ \\
\hline Liestal-LHA & LIE & Suburban, Traffic & 32.30 & $1990-2014$ & $\mathrm{D}$ \\
\hline Zürich-Kaserne & ZUE & Urban, Background & 33.27 & $1991-2014$ & $\mathrm{D}$ \\
\hline Basel-St.Johann & BSJ & Urban, Background & 34.60 & $1990-2014$ & $\mathrm{D}$ \\
\hline Lugano & LUG & Urban, Background & 35.45 & $1990-2014$ & $\mathrm{D}$ \\
\hline Zürich-Stamp/str. & ZSS & Urban, Traffic & 42.74 & $1995-2014$ & $\mathrm{E}$ \\
\hline Sion & $\mathrm{SIO}$ & Rural, Highway & 45.49 & $1990-2014$ & $\mathrm{E}$ \\
\hline Lausanne & $\mathrm{LAU}$ & Urban, Traffic & 53.87 & $1991-2014$ & $\mathrm{E}$ \\
\hline Härkingen & HAE & Rural, Highway & 68.00 & $1993-2014$ & $\mathrm{E}$ \\
\hline Bern & BER & Urban, Traffic & 82.00 & $1991-2014$ & $\mathrm{E}$ \\
\hline
\end{tabular}




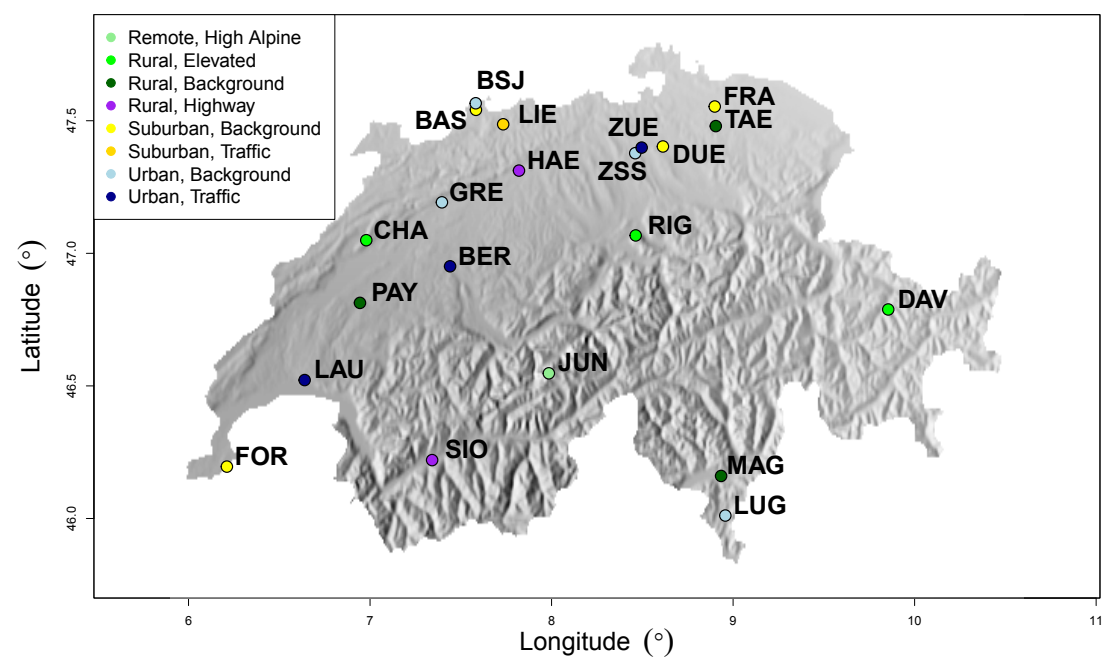

Figure 4: Map of Switzerland and location of the sites that were considered for this study. The site types are distinguished by color.

concentrations are shown as a base case. The base case approach is a commonly used and straight forward technique for trend analysis. It is apparent from Fig 5 that the resulting trend estimates for all approaches are similar in magnitude. However, the uncertainties (represented by the range of the CI) for the de-seasonalized and meteo-adjusted trends are much smaller than for the base case. The trend estimation based on de-seasonalized monthly values is advantageous compared to the analysis of annual values; the higher number of observations leads to smaller uncertainties in the trend estimation. This is especially true for the meteo-adjusted data, where the short-term variability due to the influence of meteorology on $\mathrm{O}_{3}$ has been reduced. Compared to EEMD, the parametric approach leads to higher uncertainties for the calculated trends in all stations. This is expected, because the seasonal signal derived from EEMD already captures the variation in $\mathrm{O}_{3}$ due to the influence of meteorology on the seasonal scale. For instance, the effect of the exceptionally hot summer in 2003 and 2006 on $\mathrm{O}_{3}$ is clearly visible in the seasonal signal obtained by the EEMD (Fig. 3). Ordóñez et al. (2005) have also observed high $\mathrm{O}_{3}$ concentrations 
in Switzerland during summer of 2003. In addition, Schnell et al. (2014) and

Carro-Calvo et al. (2017) have documented elevated $\mathrm{O}_{3}$ in Europe during summer of 2006. This shows that de-seasonalization based on the EEMD removes a part of the meteorological influence, and can be considered as a basic type of meteo-adjustment. In contrast, the parametric approach yields a seasonal signal that has a constant amplitude and phase for the entire measurement period.

25 We therefore conclude that de-seasonalization based on the EEMD is due to the variable amplitude and phase of the seasonal signal advantageous over the parametric approach. Consequently, further trend analysis performed within the present study is based on this method.

\subsection{Meteorological adjustment}

The relationship between the short-term variation of $\mathrm{O}_{3}$ and meteorological parameters has been estimated as described in Section 3.2. It is observed that in all sites temperature, solar radiation, humidity, CAPE and boundary layer height have a significant effect on the short-term variability of surface $\mathrm{O}_{3}$. However, there is no clear conclusion regarding surface pressure, rain and surface sensible heat flux, which in some stations appear to affect $\mathrm{O}_{3}$ significantly while in others the influence is not significant. The percentage of the variation of $\mathrm{O}_{3}$ that is explained by the model is represented by the coefficient of determination $R^{2}$. Here, the $R^{2}$ for the short-term variation $(W(t)$ estimated by EEMD) ranges between 50-64\% for the daily mean concentrations (except for Jungfraujoch with 28\%), 22-43\% for the MDA8 (Jungfraujoch:12\%) and 35-57\% for $\mathrm{O}_{x}$ (Jungfraujoch: $27 \%$ ). The $R^{2}$ for the even shorter time scales $(E(t)$ estimated by EEMD) for the daily mean concentration of $\mathrm{O}_{3}$ lies between $0.5-19 \%$, for the MDA8 0.6-8.5\% and for $\mathrm{O}_{x}$ 0.7-16\%. Analysis of the model residuals did not indicate violations of the model assumptions (homoscedasticity of residuals). An exception was the site in Liestal, therefore meteo-adjustment was not applied for this station. More details about the model results for each station are presented in the supplementary material.

The meteo-adjustment based on EEMD reduces the variability of the $\mathrm{O}_{3}$ con- 


\section{Cat. Site 1st Period 2nd Period Breakpoint}

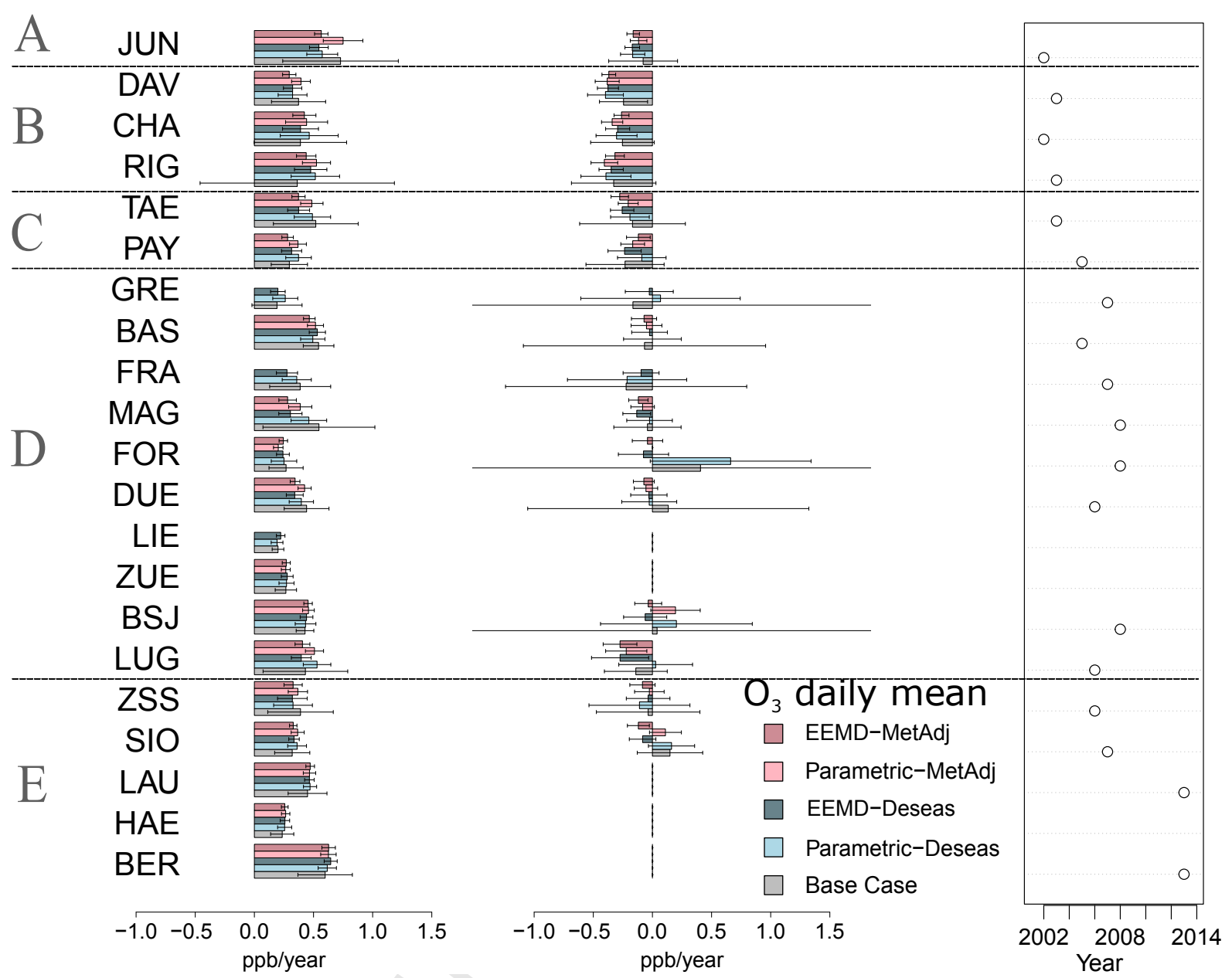

Figure 5: Bar-plots for the trends of the daily mean $\mathrm{O}_{3}$ concentrations during the identified first and second period for the five categories (indicated as Cat.). The bars show the magnitude of the Theil-Sen slopes (in ppb/year) for the studied sites (Table 1). The lines represent the $95 \% \mathrm{CI}$ of the estimated trend. The blue colors show the trends estimated from deseasonalized data, with the subtraction of the seasonal variation obtained either from the parametric approach (light blue bar) or the EEMD (dark blue bar). The pink colors show the meteo-adjusted trends based on the parametric approach (light pink bar) and EEMD (dark pink bar), respectively. The right panel indicates the time when the trend changes from positive to negative, i.e. the breakpoints as calculated from EEMD. Note that no breakpoint was found in LIE, ZUE and HAE. In LAU and BER the breakpoint occurred late, the trend in all these sites were therefore calculated for only one period. Also, the meteo-adjustment has not been applied for the sites GRE, FRA and LIE. 


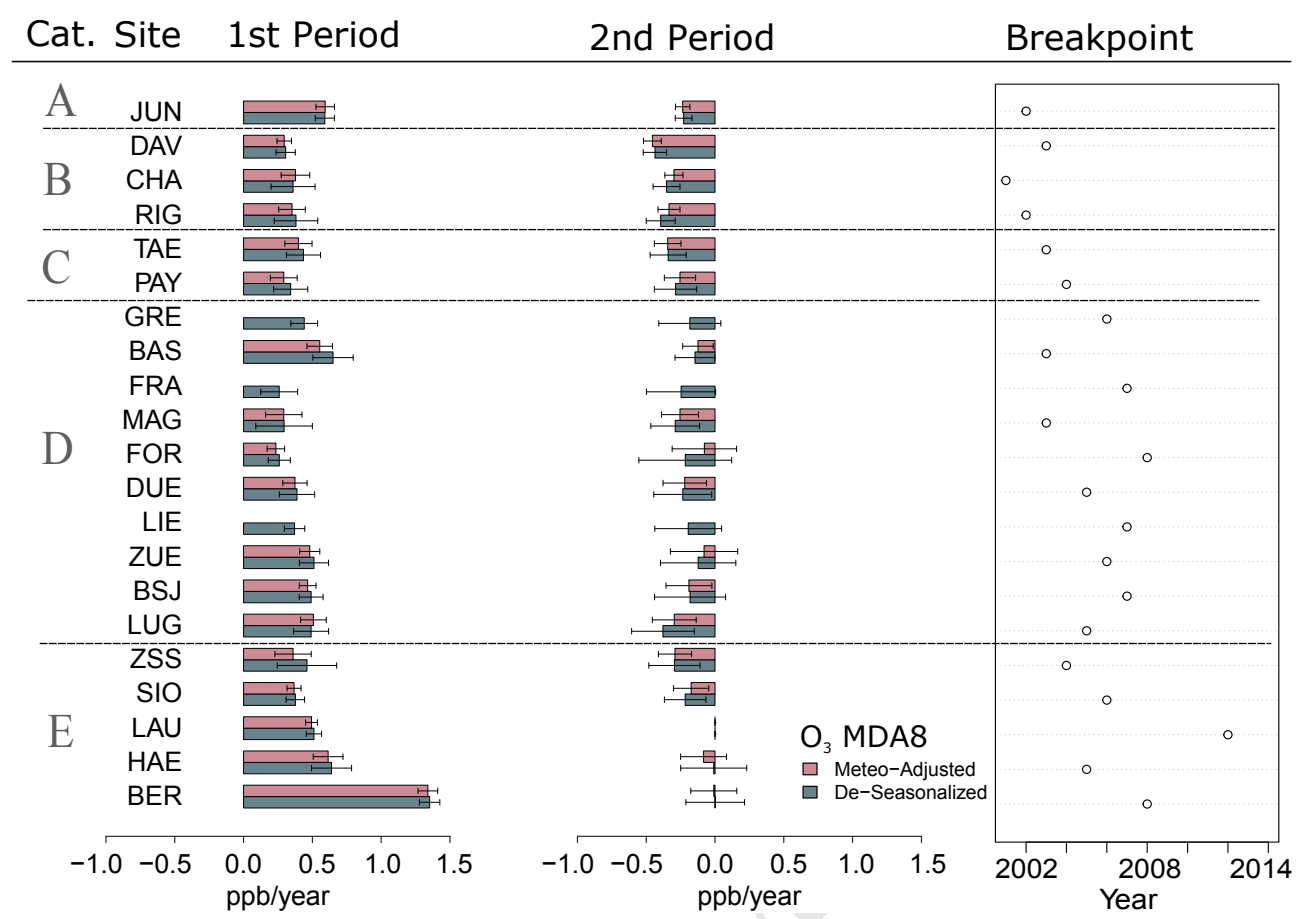

Figure 6: As for Fig. 5 but for $\mathrm{MDA} 8 \mathrm{O}_{3}$.

centrations and therefore leads to lower uncertainties when estimating trends.

${ }_{320}$ This can be seen in Figs. 5, 6] and 7] where trends of daily mean of $\mathrm{O}_{3}, \mathrm{MDA}_{8} \mathrm{O}_{3}$ and daily mean of $\mathrm{O}_{x}$ are shown. However, the effect of the meteo-adjustment procedure as described in Section 3.2 has a small effect on the trends because part of the meteorological influence on $\mathrm{O}_{3}$ has already been removed in the deseasonalization process. Furthermore, the magnitude of the trends is negligibly affected by the meteo-adjustment. We therefore propose trend estimation of $\mathrm{O}_{3}$ based on de-seasonalized data using EEMD as the most useful and robust approach, and this approach is considered in the following for the discussion of long-term trends of $\mathrm{O}_{3}$ in Switzerland.

\subsection{Trends of mean $\mathrm{O}_{3}$ in Switzerland}

330 For determination of the trend of mean $\mathrm{O}_{3}$ in similar environments, the sites have been grouped into five different site categories. The categorization 


\begin{tabular}{|c|c|c|c|c|c|}
\hline Cat. & Site & 1st Period & 2nd Peri & & Breakpoint \\
\hline A & JUN & 早 & 果 & & $\circ$ \\
\hline & DAV & E- & 傿 & & \\
\hline B & $\mathrm{CHA}$ & 믈 & 要要 & & $\circ$ \\
\hline & RIG & 星 & 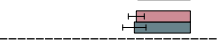 & & $\circ$ \\
\hline $\mathrm{C}$ & $\begin{array}{l}\text { TAE } \\
\text { PAY }\end{array}$ & E & 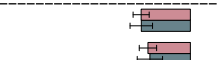 & & 。 \\
\hline & GRE & 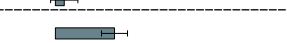 & & & \\
\hline & BAS & 置 & 要 & & 。 \\
\hline & FRA & $=$ & 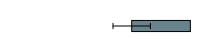 & & 。 \\
\hline & MAG & 贯 & 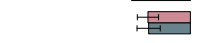 & & $\circ$ \\
\hline D & FOR & 量 & 1 & & \\
\hline & DUE & 䡒 & 傿 & & $\circ$ \\
\hline & LIE & 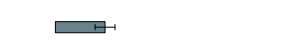 & & & \\
\hline & ZUE & 出 & 且 & & 。 \\
\hline & BSJ & 早 & I & & \\
\hline & LUG & 貫 & & & \\
\hline & ZSS & E & 量 & & $\circ$ \\
\hline & SIO & F & 要 & & 。 \\
\hline E & LAU & & 具 & O daily mean & 。 \\
\hline & HAE & 㝵 & 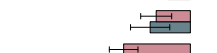 & $\square$ Meteo-Adjusted & $\circ$ \\
\hline & BER & 早 & 些 & $\square$ De-Seasonalized & ० \\
\hline & $-1.0-0.5$ & $\begin{array}{llll}0.0 & 0.5 & 1.0 & 1.5 \\
\mathrm{ppb} / \text { year } & & \end{array}$ & $\begin{array}{lll}-1.0 & -0.5 & 0.0 \\
& p p b\end{array}$ & $\begin{array}{rrr}0.5 & 1.0 & 1.5 \\
\text { /year } & & \end{array}$ & $\begin{array}{lll}2002 & 2008 & 2014 \\
& \text { Year }\end{array}$ \\
\hline
\end{tabular}

Figure 7: As for Fig. 5 but for daily mean $\mathrm{O}_{x}$.

is based on the mean $\mathrm{NO}_{x}$ mixing ratio over the entire time period at each site, indicating the proximity of the sites to emission sources of $\mathrm{O}_{3}$ precursors. The sites are grouped into categories A to E with: A the remote sites without influence from local sources $\left(\mathrm{NO}_{x} \leq 1 \mathrm{ppb}\right)$, B the background sites with very low local pollution $\left(1 \leq N O_{x} \leq 10 \mathrm{ppb}\right)$, C the rural sites with low local pollution $\left(10 \leq N O_{x} \leq 20 \mathrm{ppb}\right)$, D the suburban and urban sites with moderate local pollution $\left(20 \leq N O_{x} \leq 40 \mathrm{ppb}\right)$ and E comprising all traffic sites which are highly influenced by local emissions $\left(\mathrm{NO}_{x} \geq 40 \mathrm{ppb}\right)$. Note that the categories representing remote or rural environments (category A to C) consist of a smaller number of sites than the categories $\mathrm{D}$ and $\mathrm{E}$. This is justified by the fact that remote and rural sites have a larger spatial representativeness than suburban and urban locations, where specific site characteristics typically have a larger influence on prevailing air pollution levels. The trends of daily mean ${ }_{345} \mathrm{O}_{3}, \mathrm{MDA} 8 \mathrm{O}_{3}$ and daily mean $\mathrm{O}_{x}$ at the sites within the different categories are 
illustrated in Figs. 8, 9 and 10. The average trends of all sites in the different site categories are shown in Fig. 11 and listed in Table 2.
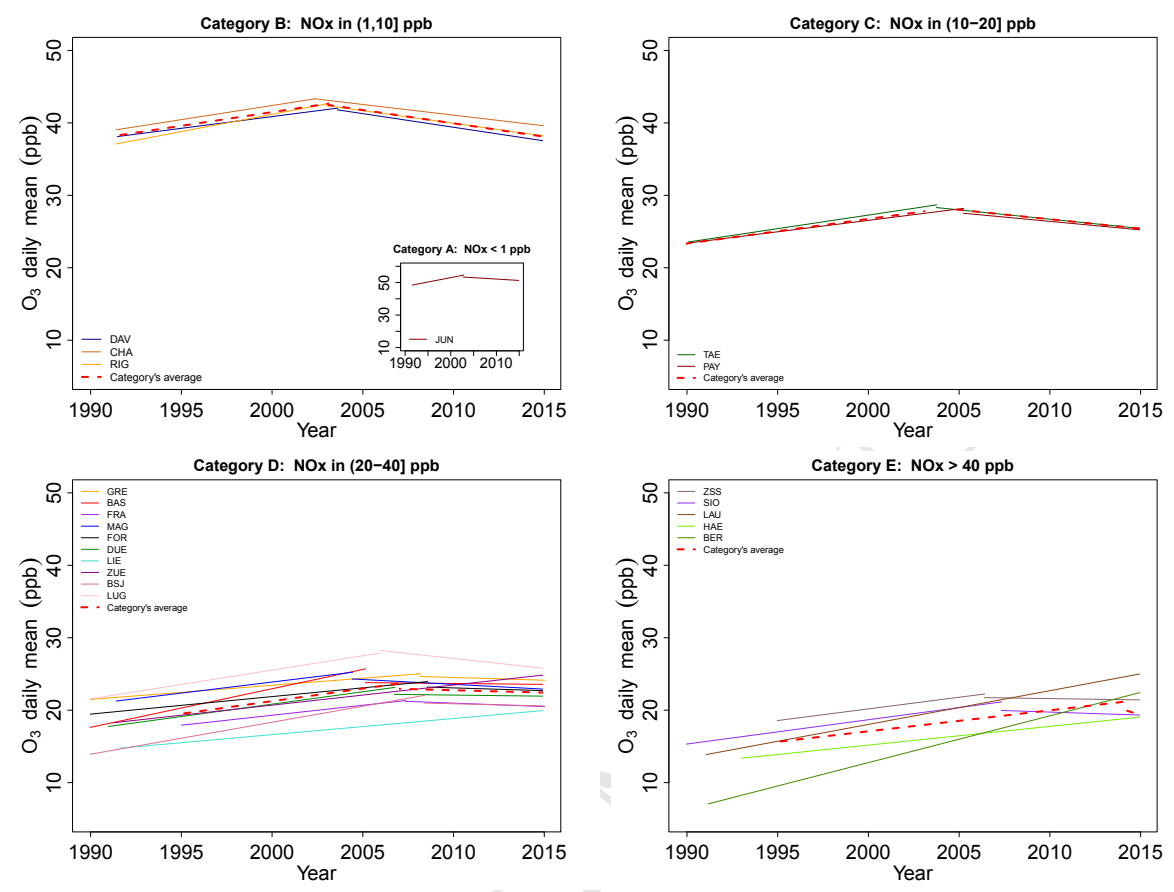

Figure 8: Theil-Sen trends of daily mean $\mathrm{O}_{3}$ concentrations estimated from monthly deseasonalized values separated for stations in categories A-E. The categories have been defined based on the prevailing $\mathrm{NO}_{x}$ mixing ratio. The averages (red dashed lines) are based on the averaged de-seasonalized time series in each category and breakpoints on the averaged $L T(t)$.

The highest $\mathrm{O}_{3}$ levels are observed at the high Alpine site at Jungfraujoch (3580 m a.s.l.), which is the only site in category A due to the exceptional characteristics and the high spatial representativeness of this site (Fig 8). At this remote location, local emissions of $\mathrm{O}_{3}$ precursors are negligible, while long-range transport phenomena are of particular importance (Balzani-Lööv et al., 2008). At Jungfraujoch, $\mathrm{O}_{3}$ (all metrics) was increasing by $\sim 0.54-0.60 \mathrm{ppb} /$ year since 1990 (Table 2), and started to decrease after 2002. The same temporal behavior of $\mathrm{O}_{3}$ has been reported by Logan et al. (2012) for Alpine sites (including Jungfraujoch), as well as for regular aircraft (MOZAIC) measurements 

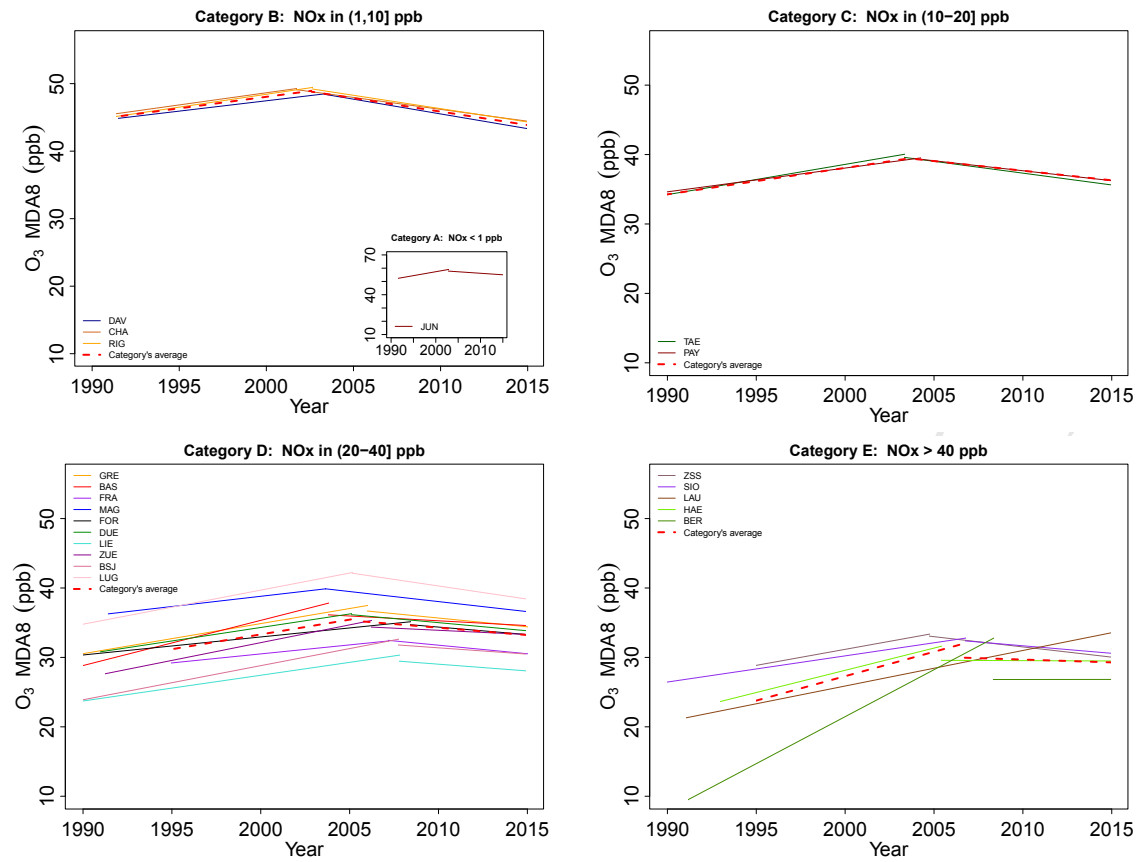

Figure 9: Theil-Sen trends of MDA8 $\mathrm{O}_{3}$ estimated from monthly de-seasonalized values separated for stations in categories A-E. The categories have been defined based on the prevailing $\mathrm{NO}_{x}$ mixing ratio. The averages (red dashed lines) are based on the averaged de-seasonalized time series in each category and breakpoints on the averaged $L T(t)$.

over Europe. The observed temporal trend can therefore be considered to represent the evolution of background $\mathrm{O}_{3}$, defined as $\mathrm{O}_{3}$ resulting from precursor emissions and transport on continental scale - including contributions from stratosphere-troposphere exchange (Cui et al., 2011). Especially after 2000s, Hess and Zbinden (2013) have documented a level off of $\mathrm{O}_{3}$ in this region. In agreement to the $\mathrm{O}_{3}$ trends observed at Jungfraujoch, many studies Derwent et al., 2007, Vingarzan, 2004, Brönnimann et al., 2002) found that background concentration of $\mathrm{O}_{3}$ has most probably been changing during the last 25 years. Derwent et al. (2007) reported increasing $\mathrm{O}_{3}$ concentrations for filtered data from Mace Head (Ireland), a remote site that represents tropospheric background conditions when winds are prevailing from the western sector. Vingarzan (2004) reported that background $\mathrm{O}_{3}$ in the Northern Hemisphere had 

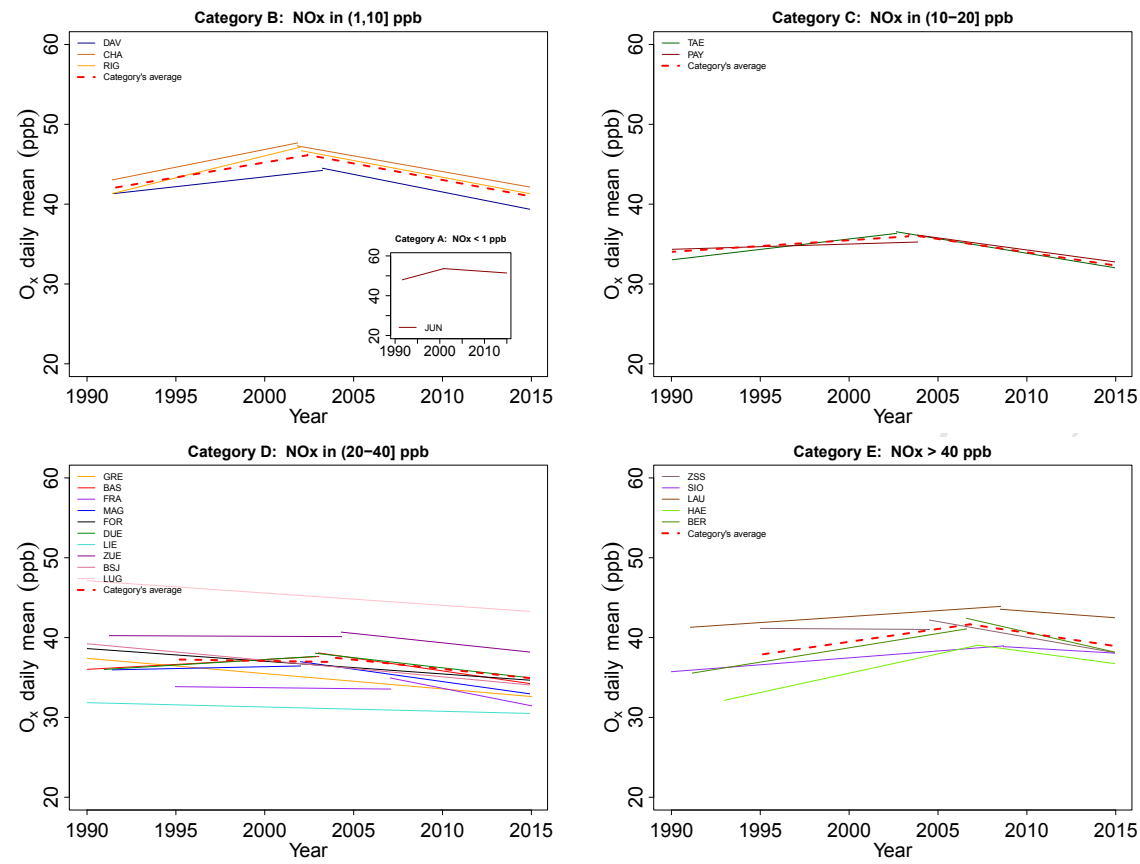

Figure 10: Theil-Sen trends of daily mean $\mathrm{O}_{x}$ mixing ratios estimated from monthly deseasonalized values separated for stations in categories A-E. The categories have been defined based on the prevailing $\mathrm{NO}_{x}$ mixing ratio. The averages (red dashed lines) are based on the averaged de-seasonalized time series in each category and breakpoints on the averaged $L T(t)$.

been increasing since the 1970 s by about $0.5-2 \%$ per year; however, the reasons for the observed trend in background $\mathrm{O}_{3}$ over Europe are not well understood. Factors that may have contributed to these changes are changes in emissions of $\mathrm{O}_{3}$ precursors on hemispheric scale and changes in the stratospheric input (Ordóñez et al., 2007; Logan et al. 2012, Hess and Zbinden, 2013). The emissions of the main precursors reactive hydrocarbons, $\mathrm{NO}_{x}$ and $\mathrm{CO}$ have been steadily decreasing in Europe and Northern America since the 1980s, whereas emissions of $\mathrm{NO}_{x}$ and $\mathrm{CO}$ were increasing in East Asia and India (Monks et al. 2015). Therefore, background $\mathrm{O}_{3}$ over Europe was increasing in the 1990s when $\mathrm{O}_{3}$ precursors from Europe and North America were decreasing and emissions in East Asia were still low compared to the other two continents (Logan et al. 2012). When background $\mathrm{O}_{3}$ over Europe started decreasing in the 2000s, total 
emissions of $\mathrm{NO}_{x}$ in China were about similar to emissions in Europe and North America and continuing to rise (Logan et al., 2012). A further important $\mathrm{O}_{3}$ precursor on the global scale is the long-lived methane $\left(\mathrm{CH}_{4}\right)$. Global emissions of $\mathrm{CH}_{4}$ have been increasing since 1950, stabilized in the 1990s and continued to rise during 2000s (Dentener et al., 2010). Therefore, the temporal changes in the global emissions of $\mathrm{CH}_{4}$ also cannot directly be linked to the observed temporal trend in background $\mathrm{O}_{3}$ over Europe. Finally, temporal changes of biomass burning might have contributed to the observed trends of $\mathrm{O}_{3}$, but the quantification of its role is beyond the scope of this study (Anderson et al. 2016. Granier et al. 2011).

The sites in category B are located in the Alps or Jura mountains at elevations above $1000 \mathrm{~m}$ a.s.l.. The $\mathrm{O}_{3}$ mixing ratio is at the sites in category $\mathrm{B}$ lower than at Jungfraujoch but higher than at the sites of categories C to E. This is often the case in elevated sites, because $\mathrm{O}_{3}$ production efficiency is higher at low $\mathrm{NO}_{x}$ regimes. The generally increasing $\mathrm{O}_{3}$ mixing ratios with increasing altitude (Seinfeld and Pandis, 2016) can be explained by higher incoming solar radiation and by the larger input of stratospheric $\mathrm{O}_{3}$ (Hess and Zbinden, 2013) at higher altitudes. In addition, sites at higher altitudes, as the ones in category B, are often sampling air in the residual layer, which is not subject to dry deposition. Compared to sites closer to the surface photochemical loss of $\mathrm{O}_{3}$ is lower at these altitudes. The influence of local sources of main $\mathrm{O}_{3}$ precursors is at the sites of category B higher than at Jungfraujoch, although still small. For example, the mixing ratio of $\mathrm{NO}$, a trace gas that can be regarded as an indicator for the proximity to anthropogenic sources, is at the sites of this category below $0.5 \mathrm{ppb}$ (mean value between 1990 and 2014). Moreover, 50-70\% of the daily maximum concentrations are associated with $\mathrm{O}_{3}$ originating in the residual layer that is formed overnight (Neu et al., 1994). Finally, vertical mixing of air masses and transport of $\mathrm{O}_{3}$ precursors from the polluted boundary layer to higher altitudes (Henne et al. 2003), as well as biogenic VOC emissions from nearby forests can contribute to $\mathrm{O}_{3}$ formation at the type of locations represented by category B. $\mathrm{O}_{3}$ mixing ratios and temporal changes at the sites of category $\mathrm{B}$ are therefore 
more strongly influenced by local and regional emissions of $\mathrm{O}_{3}$ precursors than the remote site at Jungfraujoch (category A). The trend behavior of $\mathrm{O}_{3}$ at all three sites in category B is similar and increasing at a slightly slower rate (all

The influence of changing local and regional emissions of these precursors on surface $\mathrm{O}_{3}$ is even more distinct at the sites in category D. These sites represent suburban and urban areas that are not exposed to emissions from sources in the immediate vicinity. An exception in category D is the site in Liestal, which the sites in category $\mathrm{C}$, except that the breakpoints are further shifted to later 
times (2006-2008). At some of the sites in category D no breakpoint in the daily mean $\mathrm{O}_{3}$ mixing ratio is observed, a behavior that is also apparent at some of the traffic sites in category E. Moreover, the average temporal change of $\mathrm{O}_{x}$ during the first period is for the sites in category D close to zero (-0.03 ppb/year), because some of the sites show slightly increasing $\mathrm{O}_{x}$ mixing ratios until the mid of the 2000s while at others $\mathrm{O}_{x}$ is continuously decreasing. Reasons for the diverse trends of $\mathrm{O}_{x}$ in category $\mathrm{D}$ could be that this category is broad in terms of $\mathrm{NO}_{x}$ pollution, and that $\mathrm{O}_{3}$ concentrations at those sites are differently influenced by transport of $\mathrm{O}_{3}$ that is formed several hours before in neighbored upwind regions. On average, the upward trend in $\mathrm{O}_{3}$ is at the sites in category D entirely compensated by a downward trend in $\mathrm{NO}_{2}$.

The final category $\mathrm{E}$ includes the sites with the highest levels of $\mathrm{NO}_{x}$, i.e. sites that are situated next to major roads. At the three sites with the highest average $\mathrm{NO}_{x}$ mixing ratio (Lausanne, Härkingen and Bern) mean $\mathrm{O}_{3}$ is continuously increasing since the beginning of the 1990s. As with most of the sites in category $\mathrm{D}$, the upward trend in mean $\mathrm{O}_{3}$ stopped at the two sites with the lowest $\mathrm{NO}_{x}$ levels (Zürich-Stamp/str. and Sion) in the mid of the 2000s and daily mean $\mathrm{O}_{3}$ is declining since then. The average long-term trend of daily mean $\mathrm{O}_{3}$ at the sites in category $\mathrm{E}$ leads to an upward trend of $0.29 \mathrm{ppb} /$ year; this trend has stopped only recently and a breakpoint in 2014 has been found. The observed trend for MDA8 $\mathrm{O}_{3}$ is similar to the sites in all other categories increasing during the first period and decreasing after the breakpoint. However, the upward trend during the first period is the largest in category $\mathrm{E}$ $(0.70 \mathrm{ppb} /$ year $)$, and it stops in 2006 , i.e. later than at the other site categories. The downward trend after the breakpoint is for the sites in category $\mathrm{E}$ the smallest (-0.08 ppb/year). At the sites of category E, the average trend of $\mathrm{O}_{x}$, in contrast to the suburban and urban sites in category $\mathrm{D}$, clearly increases 470 (0.32 ppb/year) until the breakpoint in 2006, when $\mathrm{O}_{x}$ started to decline at a rate of $-0.33 \mathrm{ppb} /$ year. For understanding the observed $\mathrm{O}_{3}$ trends at the sites of categories D and E, two relevant reactions need to be considered Sillman (1999): (a) the $\mathrm{NO}+\mathrm{O}_{3}$ titration reaction, which depletes $\mathrm{O}_{3}$ in presence of nearby $\mathrm{NO}$ 
emissions, and (b) the $\mathrm{NO}_{2}+\mathrm{OH}$ termination reaction that leads to reduced $\mathrm{O}_{3}$ formation with increasing $\mathrm{NO}_{x}$ to NMVOC ratios (NMVOC-limited regime). The larger reductions in ambient concentrations of $\mathrm{NO}$ over $\mathrm{NO}_{2}$ at sites $\mathrm{D}$ and $\mathrm{E}$ (Fig. 12 and higher reaction rate of reaction (a) over that of (b) FinlaysonPitts and Pitts, 2000) suggests that reduced depletion from the former reaction may be partially responsible for increased $\mathrm{O}_{3}$ concentrations near sources. However, trends in $\mathrm{O}_{x}$, which are typically insensitive to local titration effects, are greater (relative to trends in $\mathrm{O}_{3}$ ) at the traffic sites in category E compared to the sites in category D. This suggests that additional factors may play a role. For instance, directly emitted $\mathrm{NO}_{2}$ from road traffic has been increasing from around 1995 to 2010 in many European countries including Switzerland 485 Grange et al. 2017); evidenced by the smaller decrease in $\mathrm{NO}_{2}$ relative to $\mathrm{NO}_{x}$ at sites in category E compared to those in category D (Fig. 12). Furthermore, long-term trends of daily averaged $\mathrm{O}_{3}$ may include effects of reaction (b) which can become more significant outside of peak traffic periods.

The analysis of the trend of the considered metrics for average mean $\mathrm{O}_{3}$ levels shows that the implemented $\mathrm{O}_{3}$ mitigation policies in Switzerland (reductions of $\mathrm{NO}_{x}$ and NMVOC emissions) had an effect on mean $\mathrm{O}_{3}$. The $\mathrm{O}_{3}$ formation processes have been changing so that except for remote and rural locations at higher altitudes, where the temporal development of hemispheric $\mathrm{O}_{3}$ levels is the dominating factor, the differences in mean $\mathrm{O}_{3}$ at different types of locations have during the past two decades become smaller (Fig. 13). The $\mathrm{O}_{3}$ formation chemistry at urban, suburban and rural sites has become more similar (Pusede et al. 2015), and this can be expected to continue with further decreasing emissions of $\mathrm{NO}_{x}$ and NMVOCs. The time of the breakpoint in the trend might be explained by the relationship between $\mathrm{O}_{3}$ and its precursors ${ }_{500}\left(\mathrm{NO}_{x}\right.$ and NMVOCs), as conceptualized by $\mathrm{O}_{3}$ isopleth diagrams (FinlaysonPitts and Pitts, 2000, Thielmann et al., 2001). $\mathrm{O}_{3}$ isopleths are typically generated via the empirical kinetic model approach (EKMA) where maximum $\mathrm{O}_{3}$ production or concentration is described in terms of initial $\mathrm{NO}_{x}$ and NMVOC concentrations in a zero-dimensional box model. While NMVOC concentrations 
Cat. First period

A

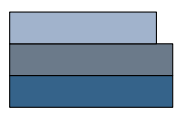

B

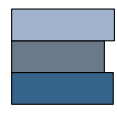

$\mathrm{C}$

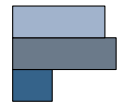

D

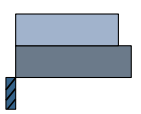

$\mathrm{E}$

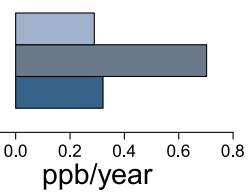

Second period
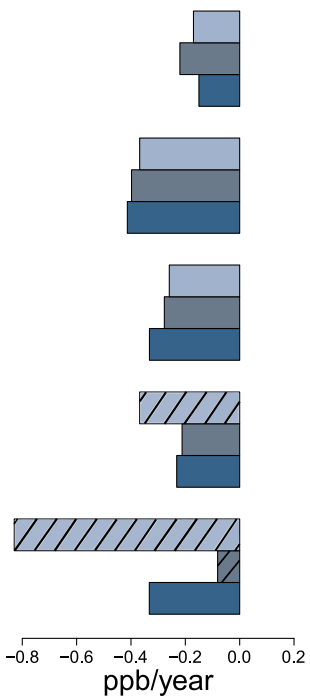

Breakpoint
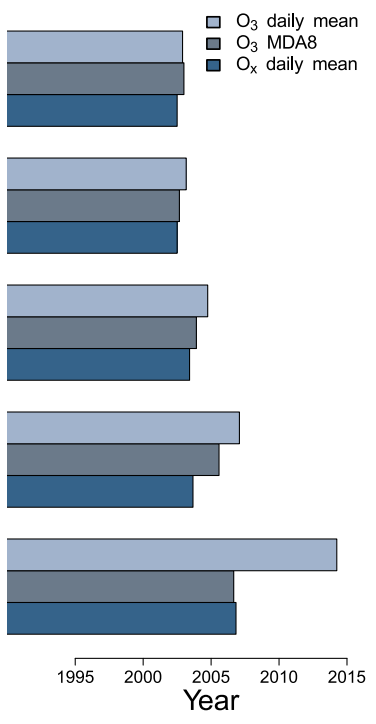

Figure 11: Trends of $\mathrm{O}_{3}$ and $\mathrm{O}_{x}$ (in ppb/year) for the site categories $\mathrm{A}$ to $\mathrm{E}$ (indicated as Cat.). Shown are the Theil-Sen trends of the averaged de-seasonalized data for each category. The two identified time periods and the breakpoint are based on the averaged $L T(t)$ at each category. The hatched bars indicate non-significant trends, i.e. with a p-value larger than 0.05 .

are not available and our analysis of $\mathrm{O}_{3}$ trends corresponds to aggregated quantities (i.e., meteorologically-adjusted monthly concentrations of daily means), we qualitatively interpret the $\mathrm{O}_{3}$ response to precursors across different concentration regimes through the same chemical mechanisms governing the isopleths. Limited studies (Dommen et al., 1995, 1999) suggest that urban and suburban sites in Switzerland with high $\mathrm{NO}_{x}$ emissions lie in the NMVOC-limited regime, where $\mathrm{O}_{3}$ formation increases with decreasing $\mathrm{NO}_{x}$ and constant NMVOC concentrations. During the 2000s, $\mathrm{NO}_{x}$ concentrations at some sites might have decreased enough so that a transition to the $\mathrm{NO}_{x}$-limited regime occurred, where $\mathrm{O}_{3}$ concentrations decrease with decreasing $\mathrm{NO}_{x}$. The late appearance of the breakpoint at highly polluted sites might be due to the much higher $\mathrm{NO}_{x}$ to NMVOC ratio level during the 1990s; the point of transition from the NMVOC- 
Table 2: Average magnitudes of the Theil-Sen trends (ppb/year) for daily mean $\mathrm{O}_{3}$ and MDA8 $\mathrm{O}_{3}$, and daily mean $\mathrm{O}_{x}$ for the two consecutive time periods in Swiss sites based on the EEMD de-seasonalization method and the time of breakpoint. P1 and P2 indicate the first and second period's average trend respectively and BP the average year of breakpoint in the trend. All numbers are based on the averaged de-seasonalized time series in each category and breakpoints on the averaged $L T(t)$. The numbers in italics are non-significant trends (p-value $>0.05)$.

\begin{tabular}{|c|c|c|c|c|c|c|c|c|c|c|}
\hline \multicolumn{5}{|c|}{ daily mean $\mathrm{O}_{3}$} & \multicolumn{3}{|c|}{$\begin{array}{lll}\text { MDA8 } & \mathrm{O}_{3}\end{array}$} & \multicolumn{3}{|c|}{ daily mean $\mathbf{O}_{x}$} \\
\hline Cat. & Environment & P1 & BP & P2 & P1 & BP & P2 & P1 & BP & P2 \\
\hline $\mathrm{A}$ & High alpine & 0.54 & 2002.9 & -0.17 & 0.60 & 2003 & -0.22 & 0.60 & 2002.5 & -0.15 \\
\hline B & $\begin{array}{l}\text { Alpine \& } \\
\text { Pre-alpine }\end{array}$ & 0.37 & 2003.2 & -0.36 & 0.34 & & -0.4 & 0.37 & 2002.5 & -0.41 \\
\hline $\mathrm{C}$ & $\begin{array}{l}\text { Rural,low al- } \\
\text { titude }\end{array}$ & 0.34 & 2004.7 & -0.26 & 0.38 & & -0.27 & 0.14 & 2003.4 & -0.33 \\
\hline $\mathrm{D}$ & $\begin{array}{l}\text { Suburban \& } \\
\text { urban }\end{array}$ & 0.37 & 2007.0 & -0.36 & 0.42 & 2005.5 & -0.21 & -0.03 & 2003.6 & -0.23 \\
\hline $\mathrm{E}$ & $\begin{array}{l}\text { Urban,high } \\
\text { pollution }\end{array}$ & 0.29 & 2014.2 & -0.83 & 0.7 & 2006.6 & -0.08 & 0.32 & 2006.8 & -0.33 \\
\hline
\end{tabular}

limited to the $\mathrm{NO}_{x}$-limited regime has not or only recently been reached. On the other hand, at rural and remote sites $\mathrm{O}_{3}$ is formed according to the $\mathrm{NO}_{x^{-}}$ limited regime (Dommen et al. 1995, 1999). We therefore assume that at rural and remote locations, the occurrence of the breakpoint is determined by changes in background $\mathrm{O}_{3}$. At locations closer to anthropogenic sources of precursors, the time of the breakpoint might be determined by the superposition of changes in background $\mathrm{O}_{3}$, reduced $\mathrm{NO}$ titration and changes in regional $\mathrm{O}_{3}$ production (Brönnimann et al., 2002, Ordóñez et al., 2005). In particular, we hypothesize

${ }_{525}$ that the latter may have been altered by a transition of $\mathrm{O}_{3}$ production to a more $\mathrm{NO}_{x}$-limited regime. 


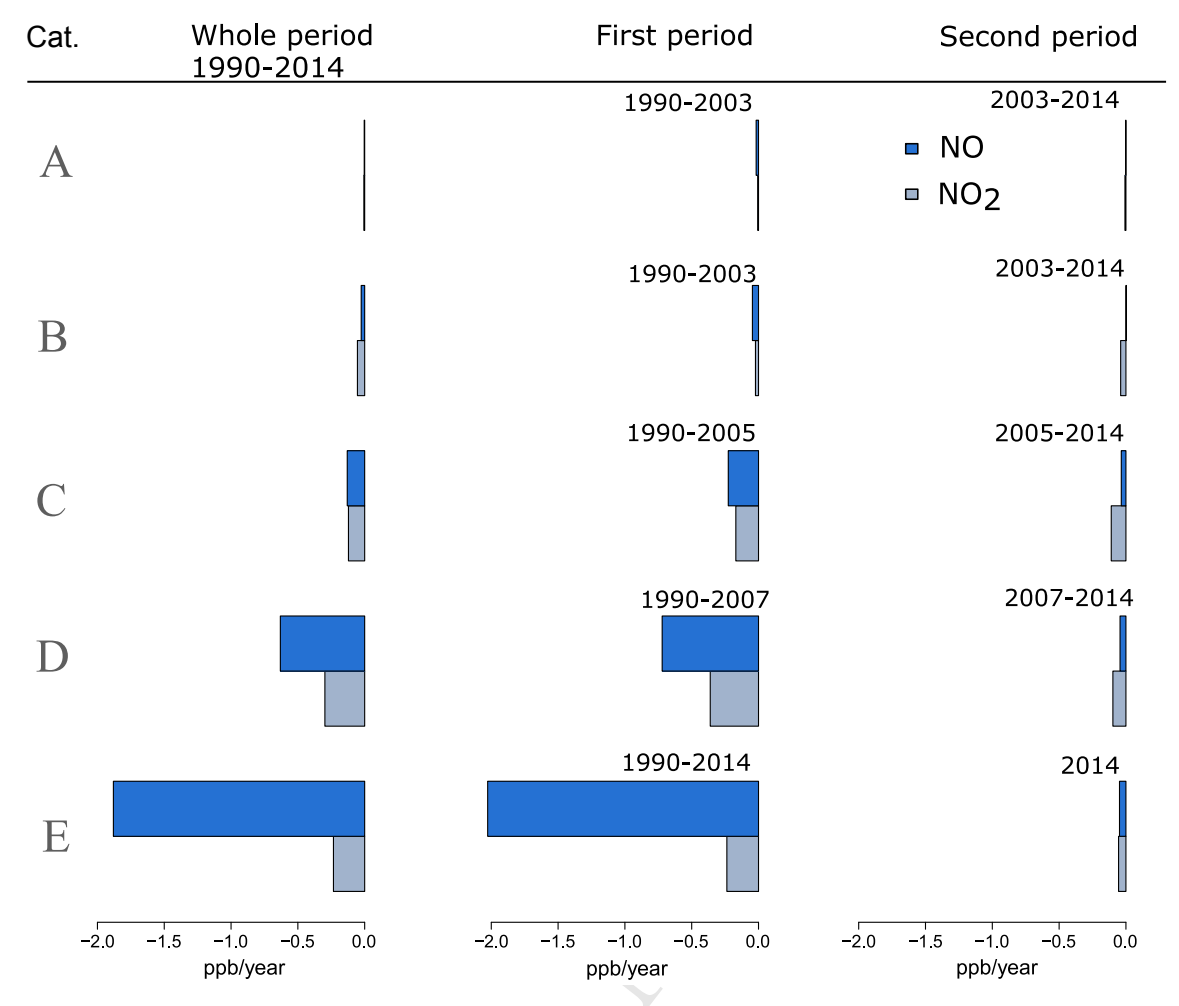

Figure 12: Bar plots with the Theil-Sen trends of daily mean $\mathrm{NO}$ and $\mathrm{NO}_{2}$ mixing ratios annually averaged for the whole studied period in ppb/year. Trends are also shown in two successive periods that correspond to the periods that were detected for the daily mean $\mathrm{O}_{3}$ mixing ratios. Stations are grouped according to mean $\mathrm{NO}_{x}$ mixing ratio levels over the studied period in categories A-E (indicated as Cat.).

\section{Conclusions}

A statistical approach for estimation of $\mathrm{O}_{3}$ trends based on time scale decomposition of multi-year observations from various surface sites in Switzerland has been applied. The non-parametric time scale decomposition (EEMD) of the time series into long-term, seasonal and short-term variations proved to be a valuable tool for a long-term $\mathrm{O}_{3}$ trend analysis. In addition, the two-regime trend calculation revealed an interesting dependance of the $\mathrm{O}_{3}$ response to precursors reductions on the station's pollution burden. The proposed EEMD-based de-seasonalization accounts for a large fraction of the meteorology driven year- 


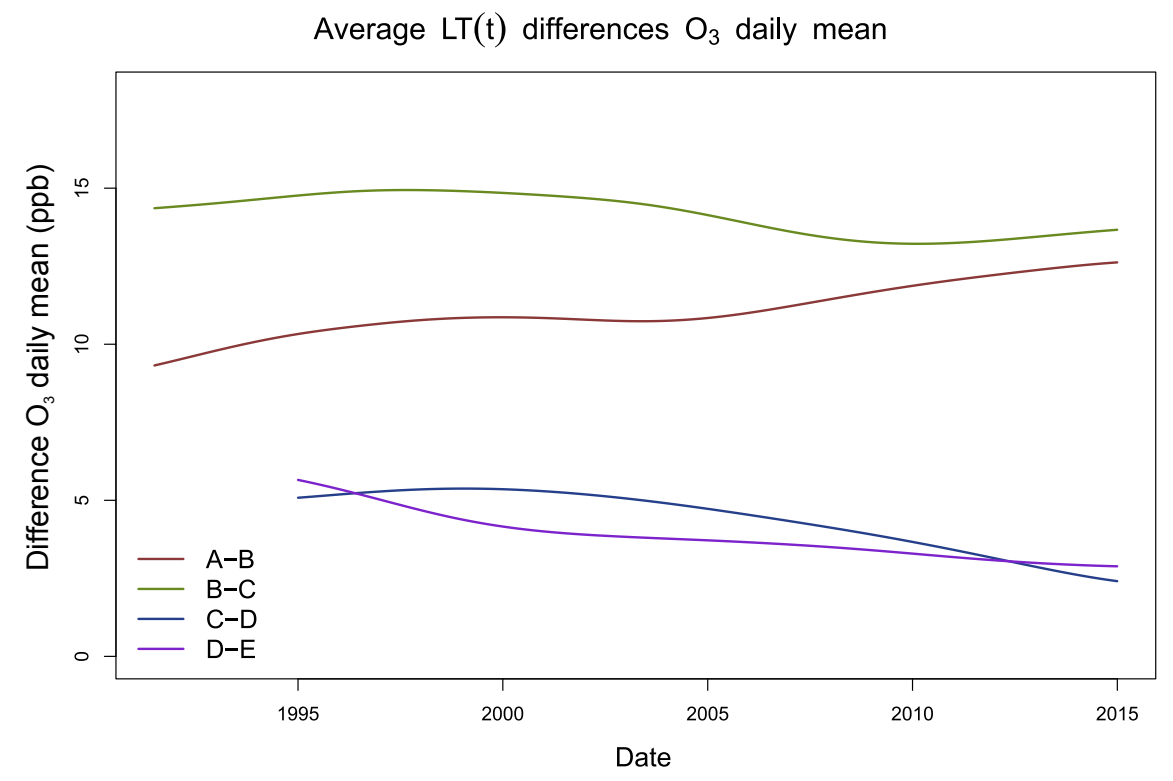

Figure 13: Differences between the categories A-E of the averaged $L T(t)$. A-B is the LT(t) difference between categories $\mathrm{A}$ and $\mathrm{B}, \mathrm{B}-\mathrm{C}$ between $\mathrm{B}$ and $\mathrm{C}$ etc.

to-year variability of $\mathrm{O}_{3}$ and allows the estimation of temporal trends of $\mathrm{O}_{3}$ with reduced uncertainties, without meteorological adjustment of the observations.

It was found that the daily mean $\mathrm{O}_{3}$ and the daily maximum of the eight hour running mean of hourly $\mathrm{O}_{3}$ mixing ratios were increasing during the $1990 \mathrm{~s}$; this trend changed around the mid of the decade of the 2000s when they started to decline. The year the upward trend of $\mathrm{O}_{3}$ stopped shows a clear dependence on the type of location. The breakpoint occurs earliest at remote sites and is shifted towards later times with increasing proximity to sources of $\mathrm{NO}_{x}$. The observed $\mathrm{O}_{3}$ trend at the remote site Jungfraujoch is interpreted as being representative for the temporal development of the $\mathrm{O}_{3}$ background over Europe. Although the temporal changes of background $\mathrm{O}_{3}$ over Europe are well described in the scientific literature, the processes leading to the observed temporal changes in background $\mathrm{O}_{3}$ are still poorly understood. At all considered locations other than the remote site Jungfraujoch, $\mathrm{O}_{3}$ trend can be understood as resulting 
from the superposition of background $\mathrm{O}_{3}$ and the temporal changes in regional photochemical $\mathrm{O}_{3}$ production. The importance of changes in the regional $\mathrm{O}_{3}$ production due to changes in $\mathrm{O}_{3}$ precursor emissions is increasing with closeness to urban environments. It is evident that the reduced titration of $\mathrm{O}_{3}$ by $\mathrm{NO}$ due to the decreasing emissions of $\mathrm{NO}_{x}$ in Switzerland and large parts of Europe since around the beginning of the 1990s had a strong effect on mean $\mathrm{O}_{3}$ mixing ratios, but, further investigation of the temporal changes of the main chemical processes for regional $\mathrm{O}_{3}$ formation is beyond the scope of this study. It was shown that the decreasing emissions of $\mathrm{NO}_{x}$ and also NMVOCs in the urban environments resulted in an $\mathrm{O}_{3}$ formation chemistry that is more similar to suburban and rural locations as seen from decreasing differences in mean $\mathrm{O}_{3}$ mixing ratios at corresponding locations. A possible transition of the urban and suburban sites from the NMVOC-limited regime to the $\mathrm{NO}_{x}$-limited regime in a conceptual $\mathrm{O}_{3}$ isopleth diagram could be used to interpret the change in trend behavior at these locations. The effect of emissions reductions can be seen in the temporal evolution of peak $\mathrm{O}_{3}$ concentrations as well, where decreasing trends are observed since the 1990s (Boleti et al., 2018). The apparent contribution of hemispheric $\mathrm{O}_{3}$ to local surface concentrations points to the importance of global efforts towards emission reductions. Combined with changing climatic conditions, where more frequent and more intense heat events are expected, controlling $\mathrm{O}_{3}$ concentrations becomes increasingly more relevant.

\section{Acknowledgements}

We acknowledge the Swiss Federal Office of Environment (FOEN) for financing the research program. We would like to thank Dr. Stephan Henne for extracting ERA-Interim meteorological variables.

\section{References}

Anderson, D.C., Nicely, J.M., Salawitch, R.J., Canty, T.P., Dickerson, R.R., Hanisco, T.F., Wolfe, G.M., Apel, E.C., Atlas, E., Bannan, T., Bauguitte, 
S., Blake, N.J., Bresch, J.F., Campos, T.L., Carpenter, L.J., Cohen, M.D., Evans, M., Fernandez, R.P., Kahn, B.H., Kinnison, D.E., Hall, S.R., Harris, N.R.P., Hornbrook, R.S., Lamarque, J.f., Breton, M.L., Lee, J.D., Percival, C., Pfister, L., Pierce, R.B., Riemer, D.D., Saiz-lopez, A., Stunder, B.J.B., Thompson, A.M., Ullmann, K., Vaughan, A., Weinheimer, A.J., 2016. A pervasive role for biomass burning in tropical high ozone/low water structures. Nature Communications 7, 1-13. doi:10.1038/ncomms10267.

BAFU, 2016. NABEL Luftbelastung 2015. Technical Report UZ-1624-D. BAFU, Swiss Federal Office of Environment, Empa, Swiss Federal Laboratories for Materials Science and Technology.

Balzani-Lööv, J.M., Henne, S., Legreid, G., Staehelin, J., Reimann, S., Prévôt, A.S.H., Steinbacher, M., Vollmer, M.K., 2008. Estimation of background concentrations of trace gases at the Swiss Alpine site Jungfraujoch (3580 m

n asl). Journal of Geophysical Research Atmospheres 113, 1-17. doi 10.1029/ 2007JD009751.

Barmpadimos, I., Hueglin, C., Keller, J., Henne, S., Prévôt, A.S.H., 2011. Influence of meteorology on PM10 trends and variability in Switzerland from 1991 to 2008. Atmospheric Chemistry and Physics 11, 1813-1835. doi: $10.5194 / \mathrm{acp}-11-1813-2011$

Boleti, E., Hüglin, C., Takahama, S., 2018. Trends of ozone maximum concentrations in switzerland based on meteorological adjustment for the period 1990-2014. under preparation .

Brönnimann, S., Buchmann, B., Wanner, H., 2002. Trends in near-surface ozone concentrations in Switzerland: The 1990s. Atmospheric Environment 36, 2841-2852. doi:10.1016/S1352-2310(02)00145-0.

Carro-Calvo, L., Ordóñez, C., García-Herrera, R., Schnell, J.L., 2017. Spatial clustering and meteorological drivers of summer ozone in Europe n. Atmospheric Environment 167, 496-510. doi 10.1016/j . atmosenv.2017.08.050 
Chang, K.L., Petropavlovskikh, I., Cooper, O.R., Schultz, M.G., Wang, T., 2017. Regional trend analysis of surface ozone observations from monitoring networks in eastern North America, Europe and East Asia. Elementa 5, $1-22$. doi $10.1525 /$ elementa.243.

Colette, A., Granier, C., Hodnebrog, O., Jakobs, H., Maurizi, A., Nyiri, A., Bessagnet, B., D'Angiola, A., D'Isidoro, M., Gauss, M., Meleux, F., Memmesheimer, M., Mieville, A., Roüil, L., Russo, F., Solberg, S., Stordal, F., Tampieri, F., 2011. Air quality trends in Europe over the past decade: A first multi-model assessment. Atmospheric Chemistry and Physics 11, 1165711678. doi:10.5194/acp-11-11657-2011.

Cui, J., Pandey Deolal, S., Sprenger, M., Henne, S., Staehelin, J., Steinbacher, M., Nédélec, P., 2011. Free tropospheric ozone changes over Europe as observed at Jungfraujoch (19902008): An analysis based on backward trajectories. Journal of Geophysical Research 116, D10304. doi:10. 1029/2010JD015154.

Dee, D.P., Uppala, S.M., Simmons, a.J., Berrisford, P., Poli, P., Kobayashi, S., Andrae, U., Balmaseda, M.a., Balsamo, G., Bauer, P., Bechtold, P., Beljaars, a.C.M., van de Berg, L., Bidlot, J., Bormann, N., Delsol, C., Dragani, R., Fuentes, M., Geer, a.J., Haimberger, L., Healy, S.B., Hersbach, H., Hólm, E.V., Isaksen, L., Kållberg, P., Köhler, M., Matricardi, M., Mcnally, a.P., Monge-Sanz, B.M., Morcrette, J.J., Park, B.K., Peubey, C., de Rosnay, P., Tavolato, C., Thépaut, J.N., Vitart, F., 2011. The ERA-Interim reanalysis: Configuration and performance of the data assimilation system. Quarterly

n Journal of the Royal Meteorological Society 137, 553-597. doi:10.1002/qj. 630 828

Dentener, F., Keating, T., Akimoto, H., 2010. Hemispheric Transport of Air Pollution, Part A: Ozone and Particulate Matter. Technical Report 11.II.E.7. UNECE.

Derwent, R., Simmonds, P., Manning, A., Spain, T., 2007. Trends over a 20-year 
period from 1987 to 2007 in surface ozone at the atmospheric research station,

口 Mace Head, Ireland. Atmospheric Environment 41, 9091-9098. doi 10.1016/ j.atmosenv.2007.08.008.

Dommen, J., Neftel, A., Sigg, A., Jacob, D.J., 1995. Ozone and hydrogen peroxide during summer smog episodes over the Swiss Plateau: measurements and model simulations. Journal of Geophysical Research 100, 8953-8966. doi:10.1029/94JD03124

Dommen, J., Prévôt, A., Hering, A., Staffelbach, T., Kok, G., Schillawski, R., 1999. Photochemical production and aging of an urban air mass. Jourq nal of Geophysical Research: Atmospheres 104, 5493-5506. doi 10.1029/ 1998JD100053.

European Parliament and Council of the European Union, 2008. Directive 2008/50/EC of the European Parliament and of the Council of 21 May 2008 on ambient air quality and cleaner air for Europe. Technical Report. European Parliament and Council of the European 650 Union. doi/http://eur-lex.europa.eu/LexUriServ/LexUriServ.do?uri= OJ:L:2008:152:0001:0044:EN:PDF,

Finlayson-Pitts, B., Pitts, J., 2000. Chemistry of the Upper and Lower Atmosphere: Theory, Experiments, and Applications. Academic Press.

Grange, S.K., Lewis, A.C., Moller, S.J., Carslaw, D.C., 2017. Lower vehicular primary emissions of $\mathrm{NO}_{i} \mathrm{sub}_{i} 2$ in Europe than assumed in policy projections. Nature Geoscience doi $10.1038 / \mathrm{s} 41561-017-0009-0$.

Granier, C., Bessagnet, B., Bond, T., Angiola, A.D., Gon, H.D.V.D., Frost, G.J., Heil, A., Kaiser, J.W., Kinne, S., Klimont, Z., Kloster, S., Lamarque, J.f., 2011. Evolution of anthropogenic and biomass burning emissions of air pollutants at global and regional scales during the 1980-2010 period. Climatic Change 109, 163-190. doi:10.1007/s10584-011-0154-1. 
Guerreiro, C.B., Foltescu, V., de Leeuw, F., 2014. Air quality status and 1) trends in Europe. Atmospheric Environment 98, 376-384. doi $10.1016 / j$. atmosenv.2014.09.017.

Guerreiro, C.B., Gonzalez Ortiz, A., de Leeuw, F., Viana, M., Horalek, J., 2016. Air quality in Europe 2016 report. Technical Report 28. EEA (European Environmental Agency). doi:10.2800/80982.

Hastie, T., Tibshirani, R., 1990. Generalized Additive Models. Statistical Science 1, 297-310. doi $10.1214 / \mathrm{ss} / 1177013604$.

Henne, S., Furger, M., Nyeki, S., Steinbacher, M., Neininger, B., de Wekker, S.F.J., Dommen, J., Spichtinger, N., Stohl, A., Prévôt, A.S.H., 2003. Quantification of topographic venting of boundary layer air to the free tropo-

口 sphere. Atmospheric Chemistry and Physics 3, 5205-5236. doi 10.5194/ acpd-3-5205-2003

675 Henschel, S., Le Tertre, A., Atkinson, R.W., Querol, X., Pandol, M., Zeka, A., Haluza, D., Analitis, A., Katsouyanni, K., Bouland, C., Pascal, M., Medina, S., Goodman, P.G., 2015. Trends of nitrogen oxides in ambient air in nine European cities between 1999 and 2010. Atmospheric Environment 117, 234241. doi $10.1016 / \mathrm{j}$. atmosenv .2015.07.013.

Hess, P.G., Zbinden, R., 2013. Stratospheric impact on tropospheric ozone variability and trends: 1990-2009. Atmospheric Chemistry and Physics 13, 649-674. doi:10.5194/acp-13-649-2013.

Huang, N.E., Shen, Z., Long, S.R., Wu, M.C., Shih, H.H., Zheng, Q., Yen, N.C., Tung, C.C., Liu, H.H., 1998. The empirical mode decomposition and the Hilbert spectrum for nonlinear and non-stationary time series analysis. Proceedings of the Royal Society of London.Series A: Mathematical, Physical and Engineering Sciences 454, 903-995. doi 10.1098/rspa.1998.0193.

Huang, N.E., Wu, Z., 2008. A Review on Hilbert-Huang Transform : Method 
and Its Applications to Geophysical Studies. Reviews of Geophysics 46, 1-23.

IPCC, 2013. Climate change 2013: The physical science basis. contribution of working group $\mathrm{i}$ to the fifth assessment report of the intergovernmental panel on climate change, 1535 pp.

Junge, C.E., 1962. Global ozone budget and exchange between stratosphere and troposphere. Tellus 14. doi 10.3402/tellusa.v14i4.9563.

Kuebler, J., Bergh, H.V.D., Russell, A.G., 2001. Long-term trends of primary and secondary pollutant concentrations in Switzerland and their response to emission controls and economic changes. Atmospheric Environment 35, 13511363. doi:10.1016/S1352-2310(00)00401-5.

Lanz, V.A., Hueglin, C., Buchmann, B., Hill, M., Locher, R., Staehelin, J., Reimann, S., 2008. Receptor modeling of C2-C7 hydrocarbon sources at an urban background site in Zurich, Switzerland : changes between 1993-1994 口 and 2005-2006. Atmospheric Chemistry and Physics 8, 2313-2332. doi 10. 5194/acp-8-2313-2008 H., Backer, H.D., Steinbacher, M., Scheel, H., Stübi, R., Fröhlich, M., Derwent, R., 2012. Changes in ozone over Europe : Analysis of ozone measurements from sondes, regular aircraft ( MOZAIC) and alpine surface sites. Journal of Geophysical Research 117, 1-23. doi 10.1029/2011JD016952.

LRTAP Convention, 2015. Draft chapter iii: Mapping critical levels for vegetation, of the manual on methodologies and criteria for modelling and mapping critical loads and levels and air pollution effects, risks and trends.

Maas, R., Grennfelt, P., 2016. Towards Cleaner Air. Scientific Assessment Report. Technical Report. EMEP Steering Body and Working Group on Effects of the Convention on Long-Range Transboundary Air Pollu- 
tion. Oslo. URL: WwW.unece.org/environmental-policy/conventions/ envlrtapwelcome/publications.html\{\%\}0ATechnical.

Monks, P.S., Archibald, A.T., Colette, A., Cooper, O., Coyle, M., Derwent, R., Fowler, D., Granier, C., Law, K.S., Mills, G.E., Stevenson, D.S., Tarasova, O., Thouret, V., von Schneidemesser, E., Sommariva, R., Wild, O., Williams, M.L., 2015. Tropospheric ozone and its precursors from the urban to the global scale from air quality to short-lived climate forcer. Atmospheric Chemistry and Physics 15, 8889-8973. doi:10.5194/acp-15-8889-2015.

National Research Council, 1992. Rethinking the ozone problem in urban and regional air pollution. National Academies Press.

Neu, U., Künzle, T., Wanner, H., 1994. On the relation between ozone storage in the residual layer and daily variation in near-surface ozone concentration-

\A case study. Boundary-Layer Meteorology 69, 221-247. doi 10.1007/ BF00708857.

Novelli, P.C., Masarie, K.A., Lang, P.M., 1998. Distributions and recent changes of carbon monoxide in the lower troposphere. Journal of Geophysical Research D: Atmospheres 103, 19015-19033. doi:10.1029/98JD01366

Ordóñez, C., Brunner, D., Staehelin, J., Hadjinicolaou, P., Pyle, J.A., Jonas, M., Wernli, H., Prévot, A.S.H., 2007. Strong influence of lowermost stratospheric ozone on lower tropospheric background ozone changes over Europe. Geophysical Research Letters 34, 1-5. doi:10.1029/2006GL029113.

Ordóñez, C., Mathis, H., Furger, M., Henne, S., Hüglin, C., Staehelin, J., Prévôt, A.S.H., 2005. Changes of daily surface ozone maxima in Switzerland in all seasons from 1992 to 2002 and discussion of summer 2003. Atmospheric Chemistry and Physics 5, 1187-1203. doi 10.5194/acp-5-1187-2005.

Pusede, S.E., Steiner, A.L., Cohen, R.C., 2015. Temperature and Recent Trends in the Chemistry of Continental Surface Ozone. Chemical Reviews 115, 38983918. doi:10.1021/cr5006815. 
R Development Core Team, 2017. R: A Language and Environment for Statistical Computing. R Foundation for Statistical Computing. Vienna, Austria. URL: http://www.R-project.org. ISBN 3-900051-07-0.

Schnell, J.L., Holmes, C.D., Jangam, A., Prather, M.J., 2014. Skill in forecasting extreme ozone pollution episodes with a global atmospheric chemistry model. Atmospheric Chemistry and Physics , 7721-7739doi 10.5194/ acp-14-7721-2014

Seinfeld, J., Pandis, S., 2016. Atmospheric Chemistry and Physics: From Air Pollution to Climate Change. John Wiley, Hoboken, NJ.

Sen, P., 1968. Estimates of the regression coefficient based on Kendalls tau.

q Journal of American Statistical Association 63, 1379-1389. doi 10.1080/ 01621459.1968 .10480934

Sillman, S., 1999. The relation between ozone, NOx and hydrocarbons in urban and polluted rural environments. Atmospheric Environment 33, 1821-1845. doi:10.1016/S1474-8177(02)80015-8, arXiv:0902.4394v1.

Simpson, D., 1995. Biogenic emissions in Europe 2 . Implications for ozone

4 control strategies. Journal of Geophysical Research 100, 22891-22906. doi-10. 1029/95JD01878.

Stiller, B., Bocek, T., Hecht, F., Machado, G., Racz, P., Waldburger, M., 2000. NABEL-Luftbelastung 1999. Technical Report 196pp. BUWAL (Swiss Agency for Environment, Forests, and Landscape). A., Foster, C., Gerasopoulos, E., Gäggeler, H., James, P., Kentarchos, T., Kromp-Kolb, H., Krüger, B., Land, C., Meloen, J., Papayannis, A., Priller, A., Seibert, P., Sprenger, M., Roelofs, G., Scheel, H., Schnabel, C., Siegmund, P., Tobler, L., Trickl, T., Wernli, H., Wirth, V., Zanis, P., Zerefos, C., 2003. Stratosphere-troposphere exchange: A review, and what we 
have learned from STACCATO. Journal of Geophysical Research 108, 8516. doi $10.1029 / 2002$ JD002490.

Theil, H., 1950. A rank-invariant method of linear and polynomial regression analysis, part 3, in: Proceedings of Koninalijke Nederlandse Akademie van Weinenschatpen A, pp. 1397-1412. doi:10.1007/978-94-011-2546-8_20.

Thielmann, A., Prévôt, A., F.C., G., Staehelin, J., 2001. Empirical ozone isopleths as a tool to identify ozone production regimes. Geophysical Research Letters 28, 2369-2372. doi 10.1029/2000GL012787.

Thoning, K.W., Tans, P.P., Komhyr, W.D., 1989. Atmospheric carbon dioxide at Mauna Loa Observatory: 2. Analysis of the NOAA GMCC data, 19741985. Journal of Geophysical Research 94, 8549. doi:10.1029/JD094iD06p08549

Vingarzan, R., 2004. A review of surface ozone background levels and trends.

口. Atmospheric Environment 38, 3431-3442. doi 10.1016/j.atmosenv.2004. 03.030 .

Weusthoff, T., 2011. Weather Type Classification at MeteoSwiss - Introduction of new automatic classification schemes. Technical Report 235. MeteoSwiss.

Wilson, R.C., Fleming, Z.L., Monks, P.S., Clain, G., Henne, S., Konovalov, I.B., Szopa, S., Menut, L., 2012. Have primary emission reduction measures reduced ozone across Europe? An analysis of European rural background ozone trends 19962005. Atmospheric Chemistry and Physics 12, 437-454. doi: $10.5194 /$ acp-12-437-2012.

Wood, S., 2006. Generalized Additive Models: An Introduction with R. Chapman \& Hall/CRC press.

World Health Organization, 2013. Review of evidence on health aspects of air pollution: Revihaap project: final technical report.

Wu, Z., Huang, N.E., 2009. Ensemble Empirical Mode Decomposition: A noiseassisted data analysis method. Advances in Adaptive Data Analysis 1, 1-41. doi:10.1142/S1793536909000047. 
- Non-parametric time scale decomposition is valuable for identifying $\mathrm{O}_{3}$ variations

- De-seasonalization of $\mathrm{O}_{3}$ observations reduces trend uncertainty

- Trends in Switzerland increase until mid-2000s and decrease afterwards

- Decrease of $\mathrm{O}_{3}$ is delayed in highly polluted locations

- Trend in remote sites is driven by changes in background $\mathrm{O}_{3}$

- Differences amongst site types become smaller after NOx and VOC reductions 